\title{
المستخلص
}

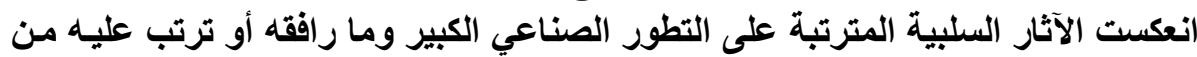

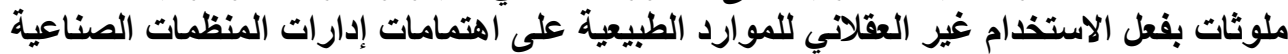

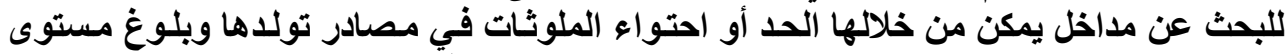

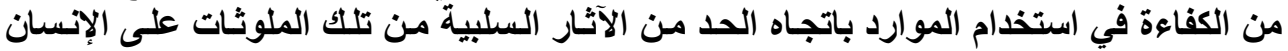

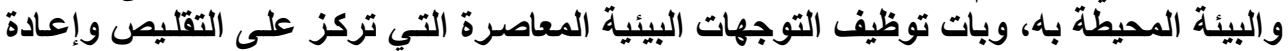

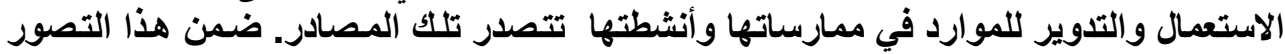

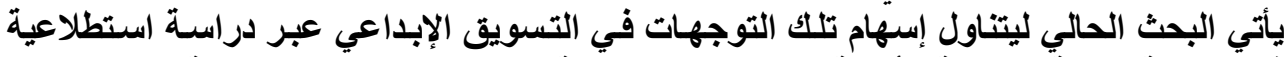

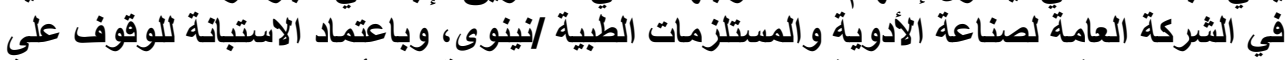

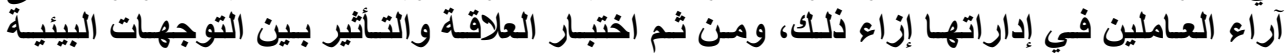

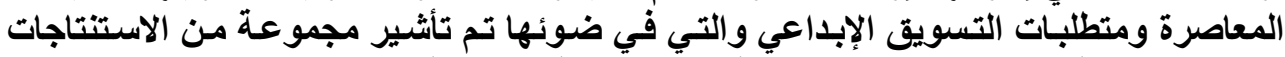

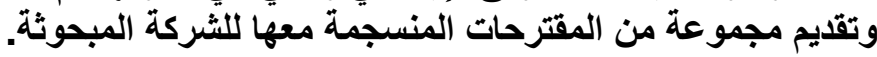

$$
\text { الكلمات المفتاحية: التوجهات البيئية، التسويث الإبداعي }
$$

\section{The Contemporary Environmental Orientations And Its Reflection On Creative Marketing: A Pilot Study In State Company For Drugs Industries And Medical Appliances In Ninevah}

Adel Th. Al-Nema (PhD)

Assistant Professor

Department of Industrial Management

University of Mosul
Raad A. Raoof (PhD)

Lecturer

Department of Industrial Management

University of Mosul

\section{Abstract}

The negative effects of industrial development and pollution as a result of irrational use of natural products have been reflected in the interests of industrial organizations. This happened to search for new aspects to limit the pollutants from their sources to attain an 
utmost level of capacity of using the resources in a way that put an end to the negative effects on both human and environment. Therefore, the use of contemporary environmental orientations based on the reduction and reuse of the recourses is at the head of the list of these approaches. On this perspective, the present research tackles contributions of these orientations in creative marketing through a survey study in State Company for Drug Industrial and Medical Appliances in Ninevah. The questionnaire has been done in order to take the pinion of the administration staff members. It studies the influence and the relation between the contemporary environment and creative marketing requirements .On the light of this test, a number of conclusions are drawn and also a number of propositions suitable for the company are presented.

$\underline{\text { Key words: }}$ Environmental Orientation, Creative Marketing

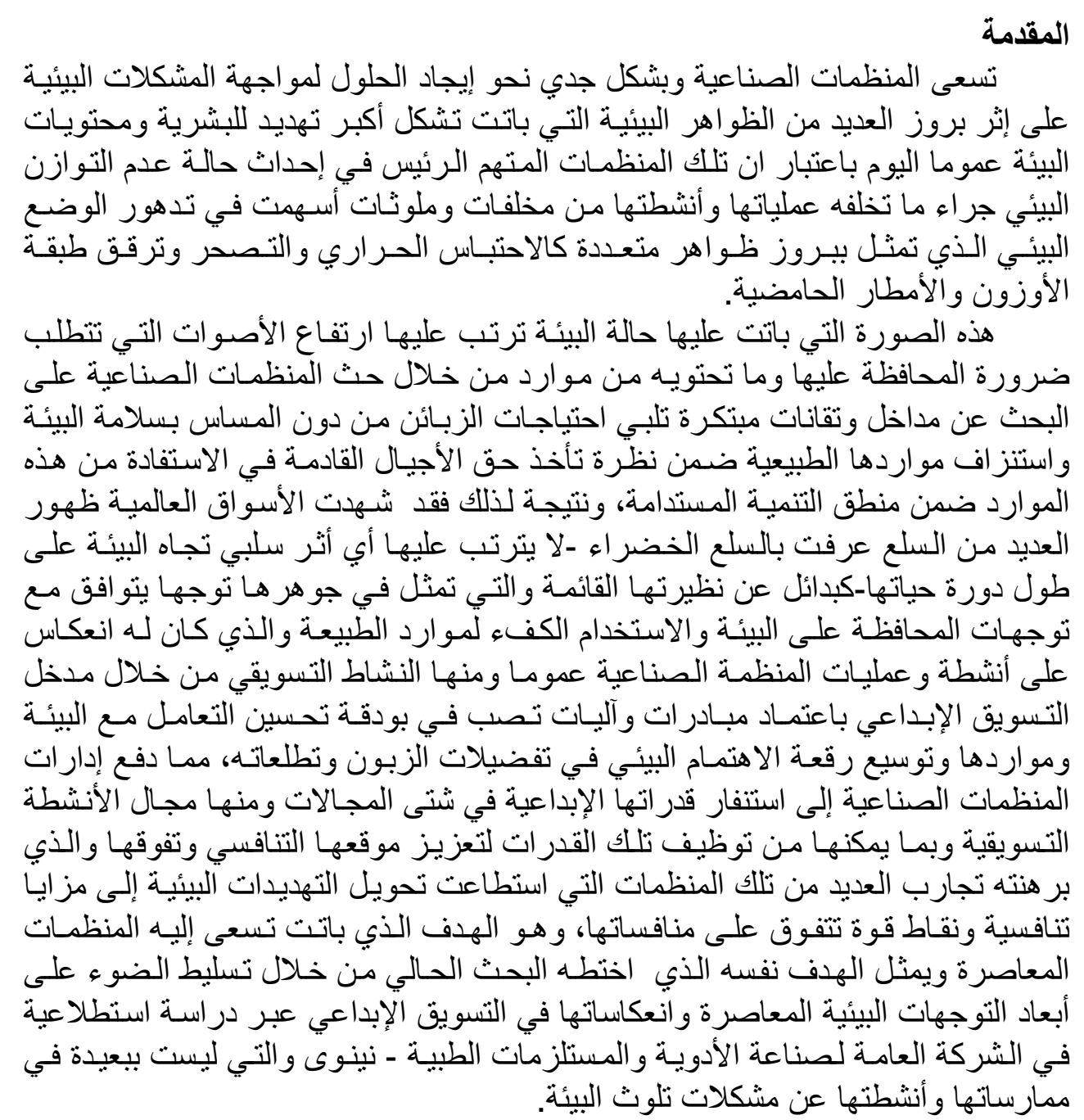




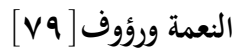

\section{منهجية البحث \\ مشكلة البحث البث}

تو اجه إدارات المنظمـات الصناعية اليوم حالة من القلق جر اء تفاقم الوضع البيئي

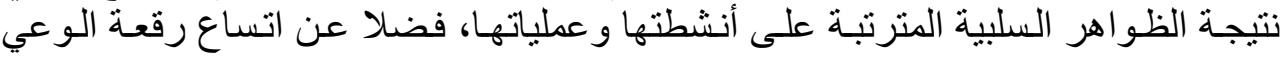

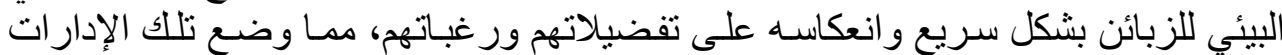

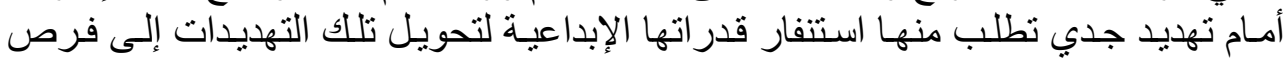

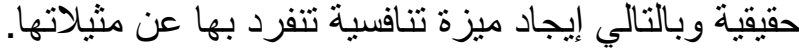

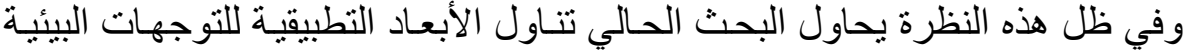

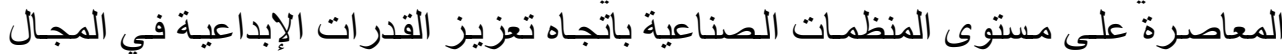

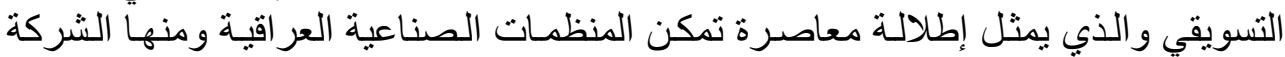

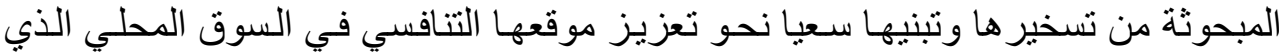

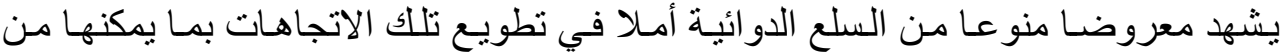
دخول السوق الإقليمية على الأقل مستقبلا. و على هذا الأساس تم صياغة الأسئلة الاتية التي تثكل إطار مشكلة البحث:

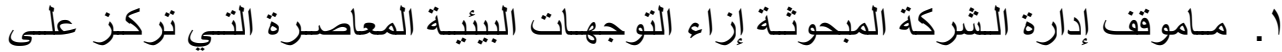

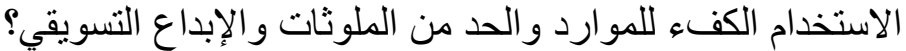

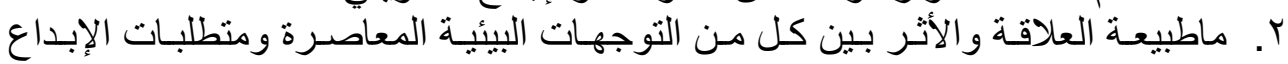

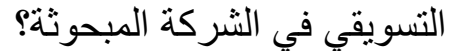
rا. هل يمكن تعزيز الإبداع التسويقي في الثركة المبحوثة من خلال تبني التوجهات البيئية

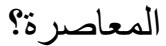

تتبثق أهمية البحث من طبيعة موضو عه، وتتجلى تلك الأهمية من خلال إبراز دور

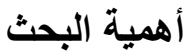

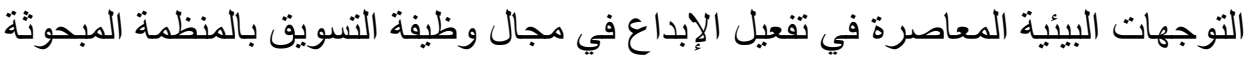

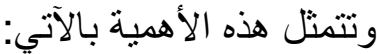

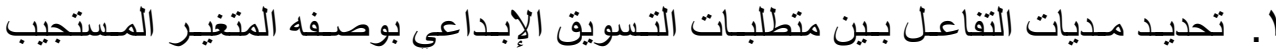

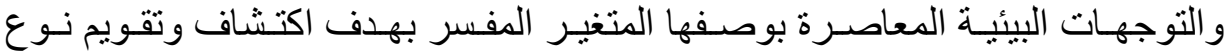
ومسنوى تلإك العلاقة ومعنويتها إلحصائيا.

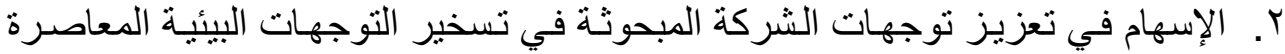

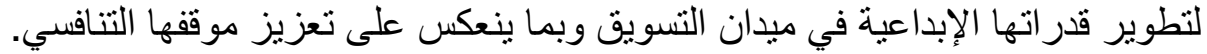

$$
\begin{aligned}
& \text { أهداف البحث المث } \\
& \text { يتمثل الهدف الرئيس للبحث في تشخيص وتحليل العلاقة والأثر للتوجهات البيئية }
\end{aligned}
$$

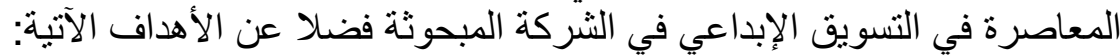

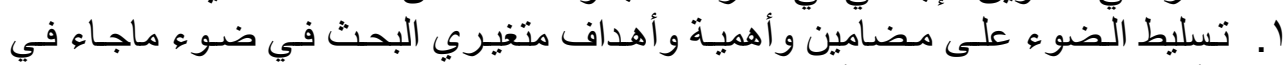

$$
\begin{aligned}
& \text { الأدبيات ذات العلاقة التي أتيحت للباحثين. }
\end{aligned}
$$




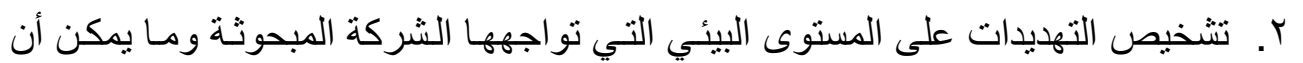

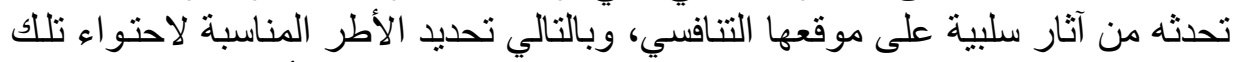

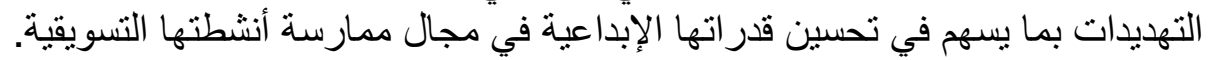

$$
\text { فرضيات البحث }
$$

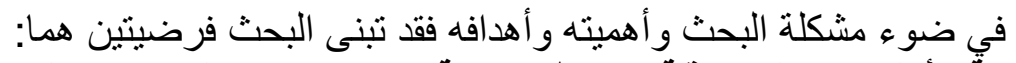

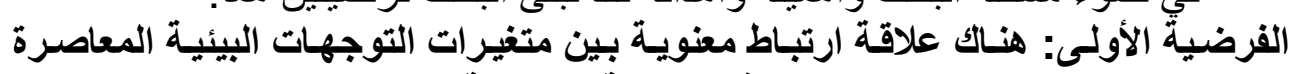

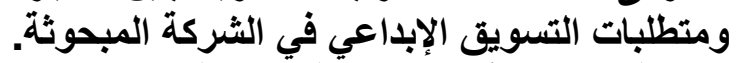

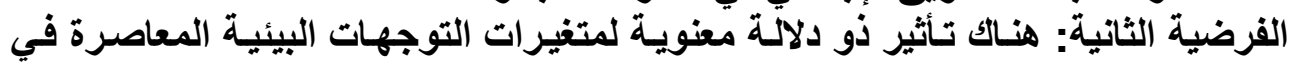
متطلبات التسويق الإبداعي في الثركة المبحة فيحوثة.

تم اختيار الثركة العامة لصناعة الأدوية والمستلزمات الطبية- نينوى ميداناً لإجر اء ألهاء

$$
\text { المجالات المكاني }
$$

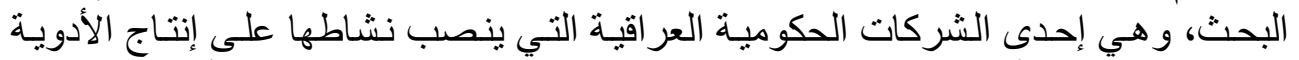

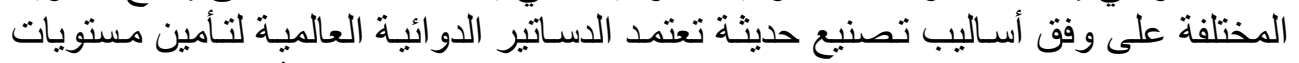

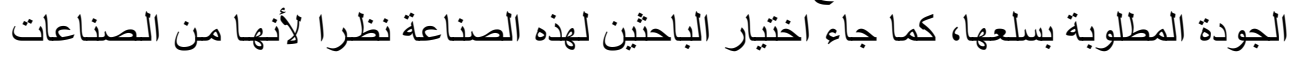

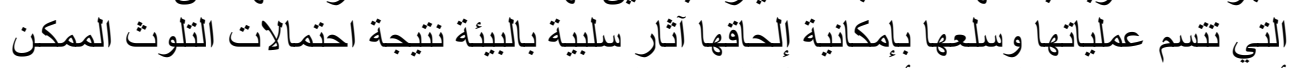

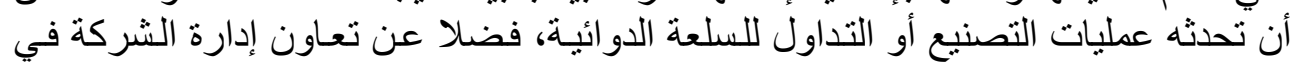

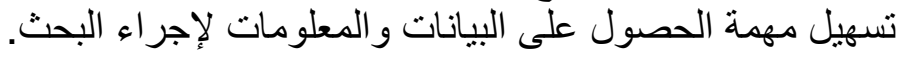

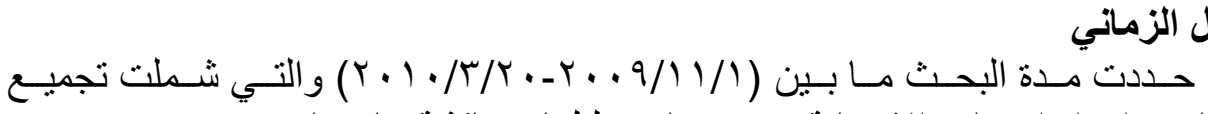
المصادر و إعداد استمارة الاستبانة وتوزيعها وتحليلها و وناقنتة نتائجها.

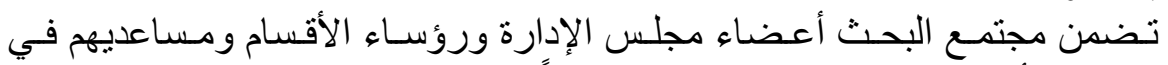

مجتمع البحث وعينته الثركة المبحوثة، أما عينة البحث فقد شملت . ب فرداً وزعت عليهم استمارة الاستبانة.

$$
\text { أساليب جمع البيانات }
$$

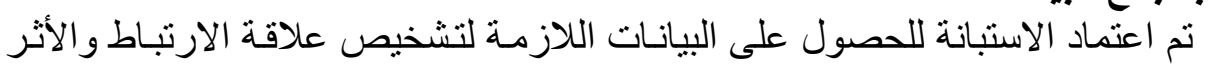

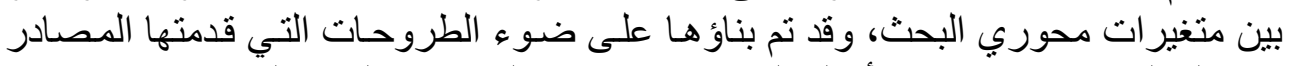

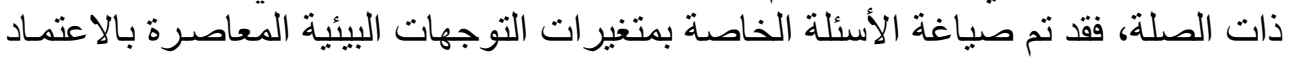

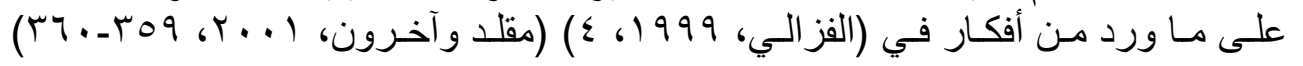

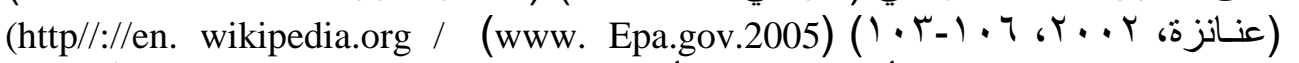

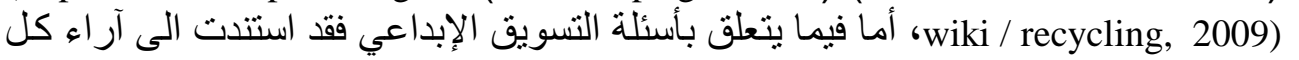

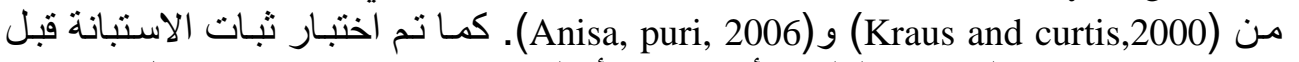

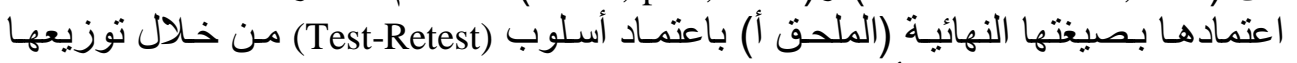

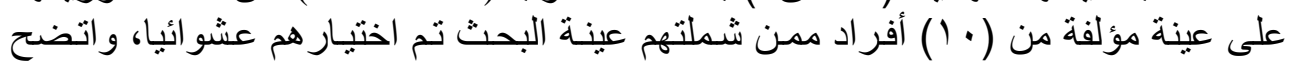




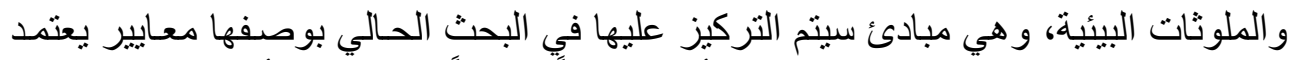

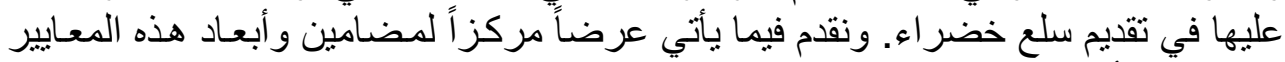

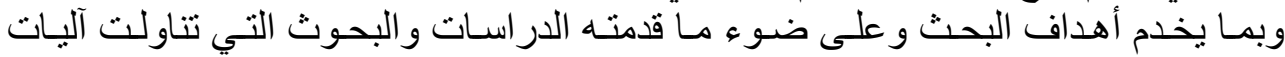

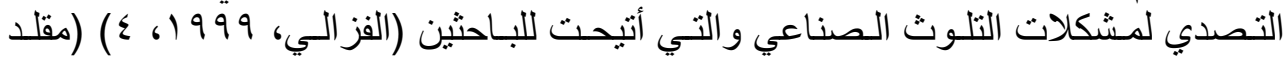

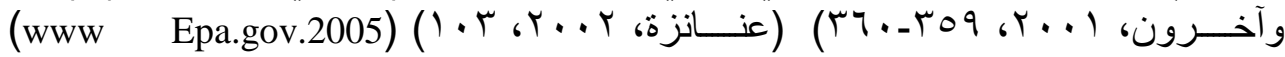

(http//://e. wikipedia.org / wiki / recycling 2009)

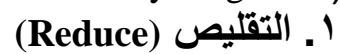

ويتصدر قمة الهرم لإستر اتيجية منع التلوث، لأنه يركز على الحد من توليد النفايات

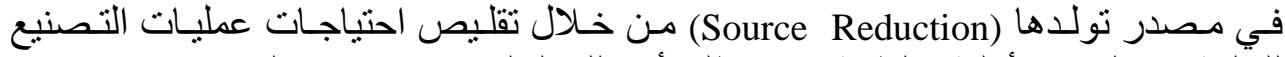

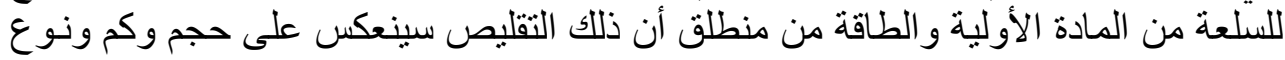

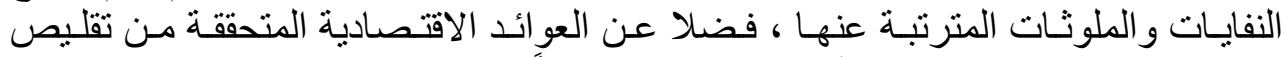

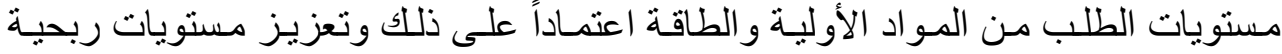

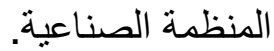

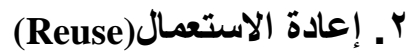

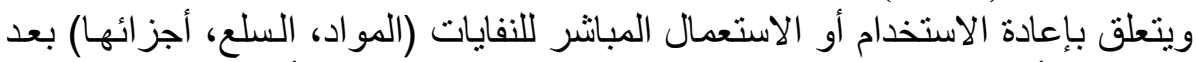

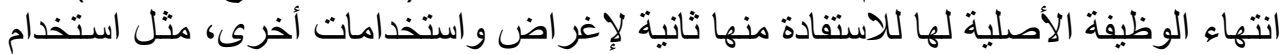

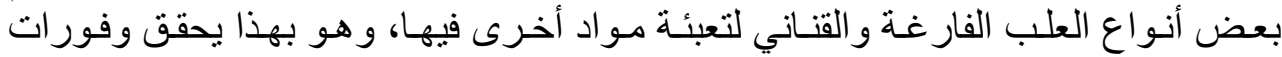
اقتصادية للمنظمة الصناعية من خلال تقليص تكاليف شر اء مو الئر اد جديدة.

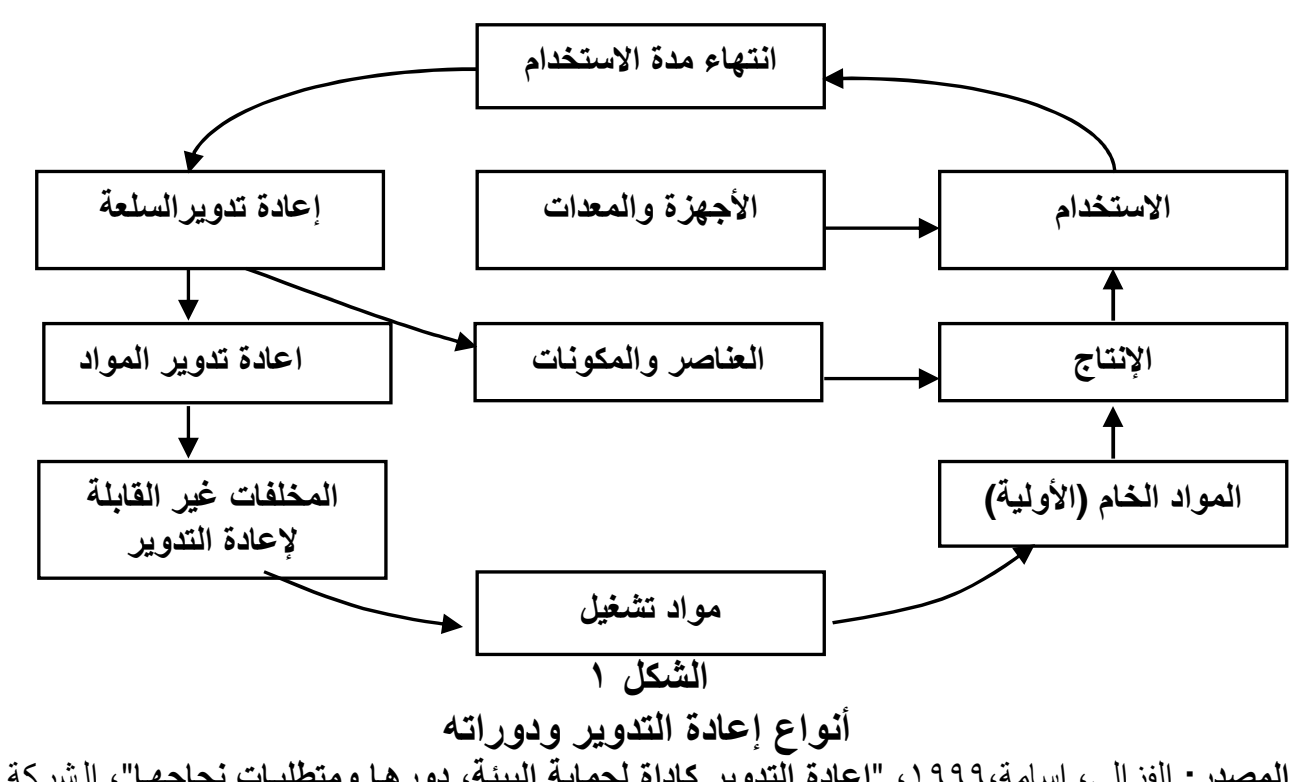

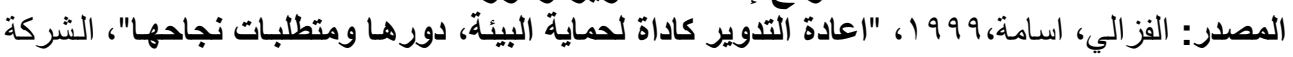

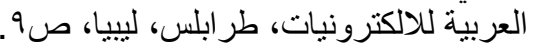

الفكرة الجوهرية لإعادة التدوير هي استحداث أو استكمال الدوائر المغلقة للاستفادة

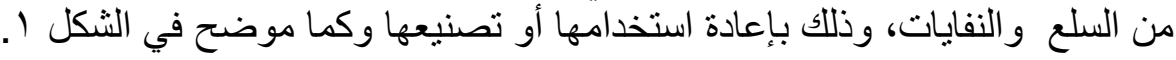




\section{[النعمة ورؤوف[^]}

وتؤدي هذه الصورة للحد من النفايـات دوراً مهماً في حمايـة البيئة ومحتو ياتها من

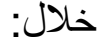

ا. ـالمحافظة على الموارد الطبيعية من خلال تقليص استنز اف المو اد الخـام و الطاقة نتيجة

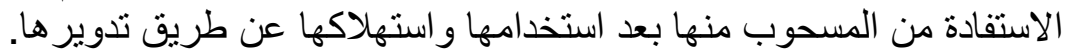
r. حماية الأراضي الزراعية والبيئة الحياتية (الإنسان، الحيوان، النبات) من الآثار السلبية

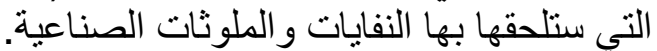

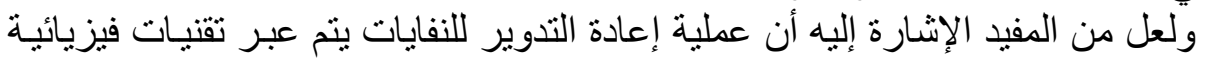

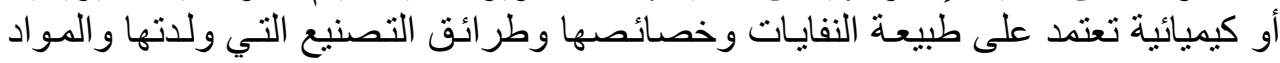

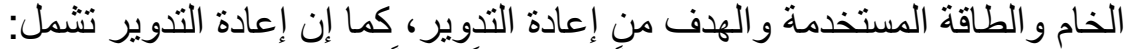

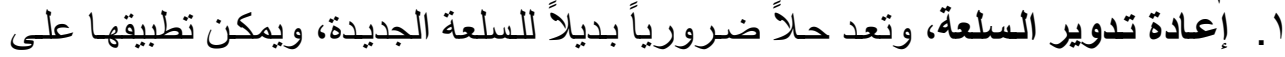

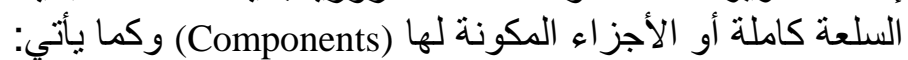

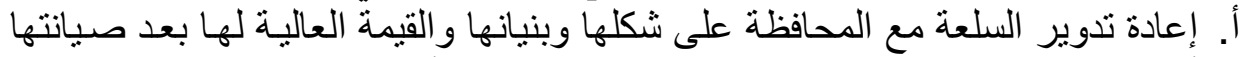

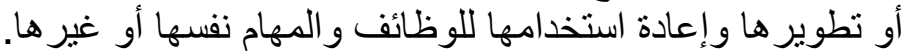

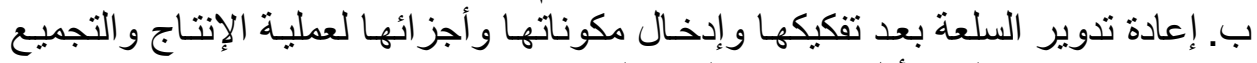

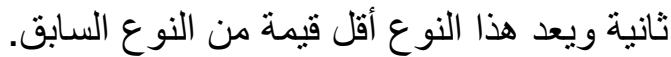

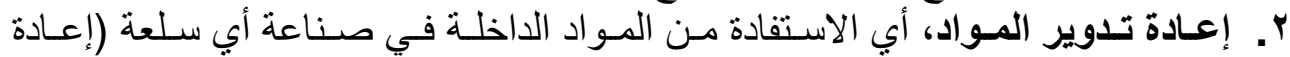

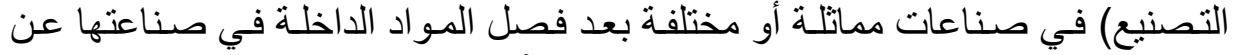
بعضها البعض مع مع مر اعاة شروط حمات ماية البعة البيئة كالآتي: ت. إعادة تدوير المواد من خلال إعادة تصنيعها واستخدامها كمواد اد تشغيل.

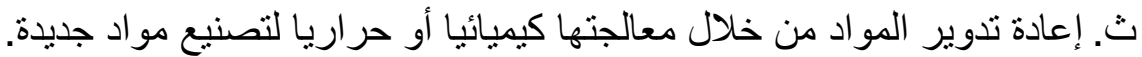

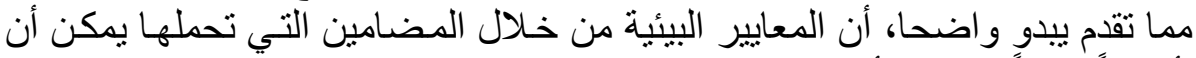

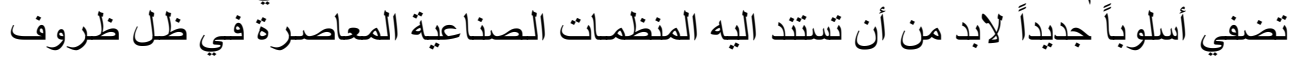

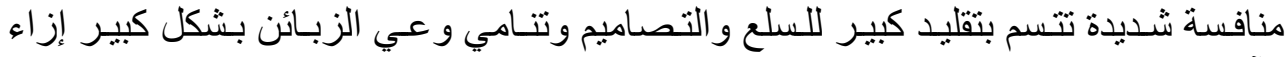

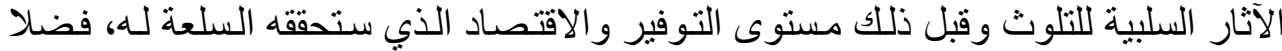

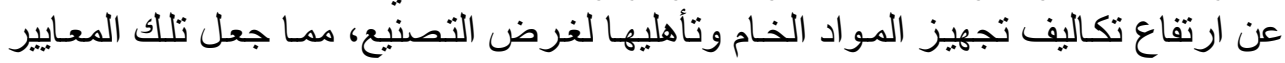

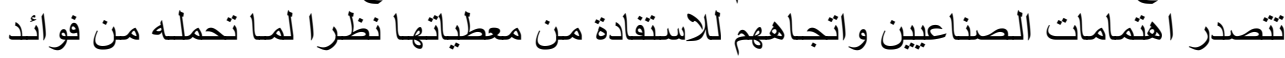
ومنافع اقتصادية كبيرة.

r. التسويق الإبداعي: إطار عام

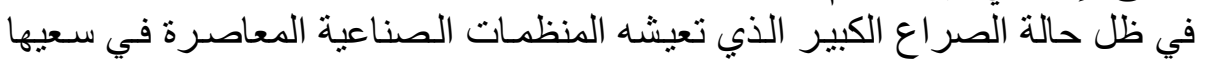

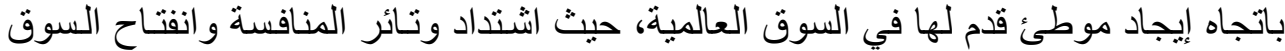

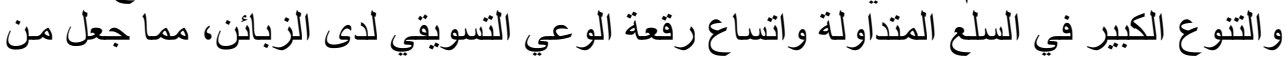

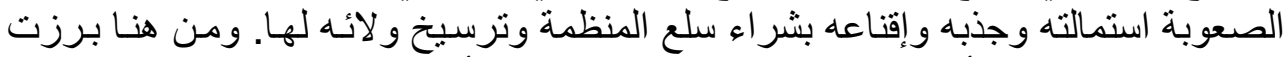

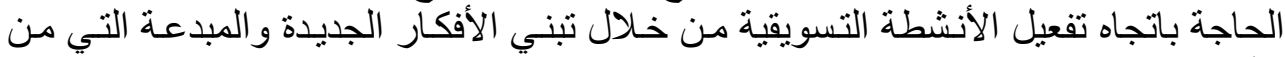

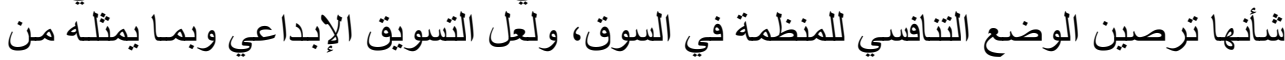

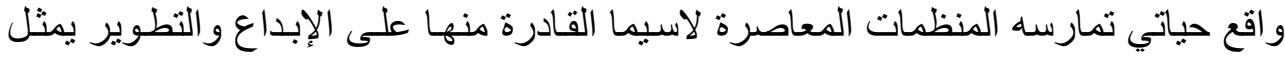

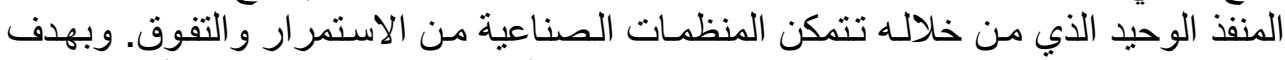

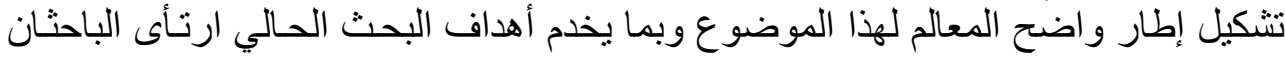
تغطيته من خلال المحاور الآتية: 


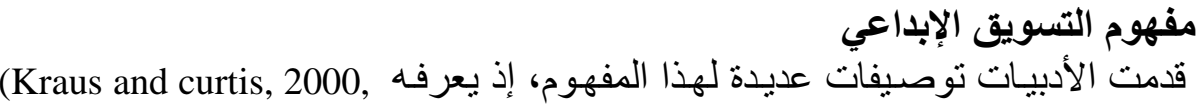

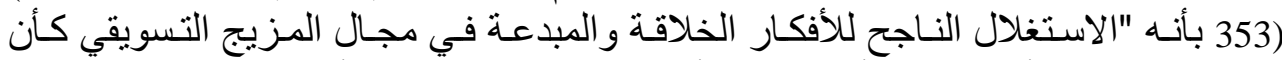

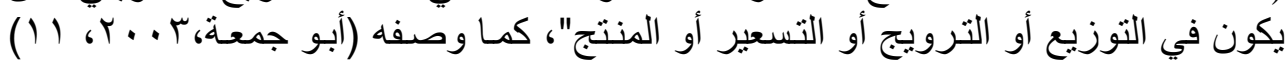

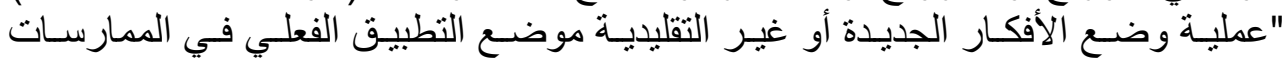
التسويقية"، وهو بهذا الوصف الثية التير إلى عملية تقديم شيء جديد في السوق يمكن أن يكون

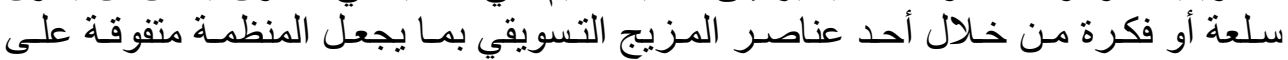
منافسيها في السوق، ويؤكد هذا التشخيص لمفهوم التسويق الإبداعي (Vervest 2005,119)

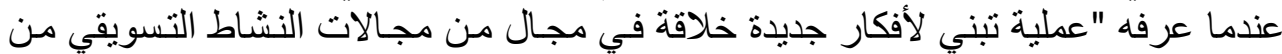

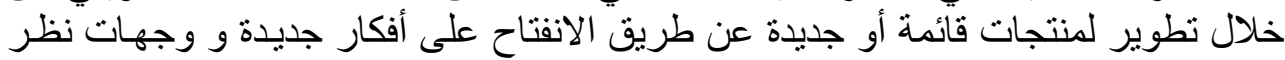

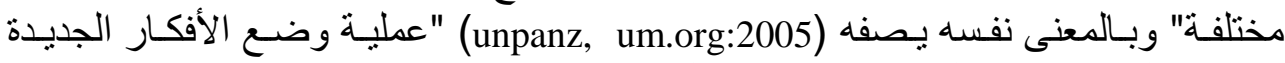
و غير التقليدية موضع التطبيق الفعلي في الممارسات التسويقية".

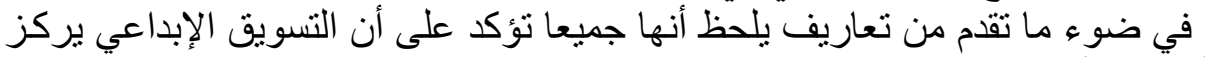

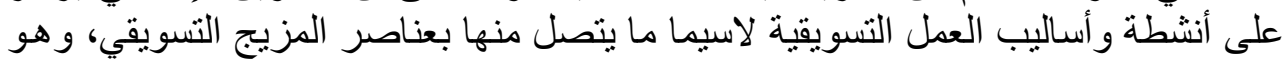

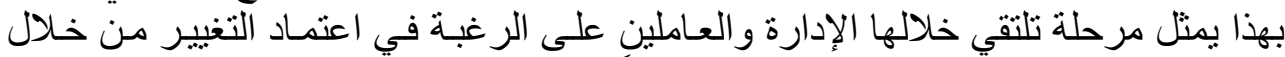

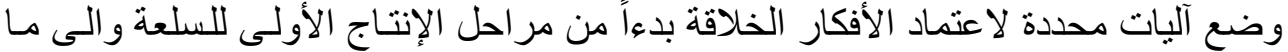

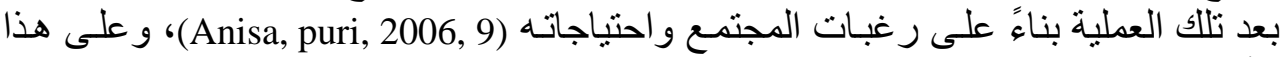

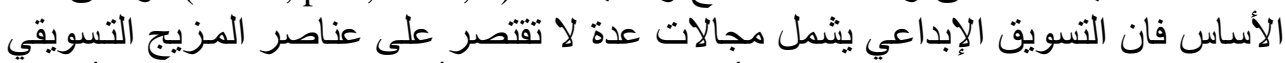

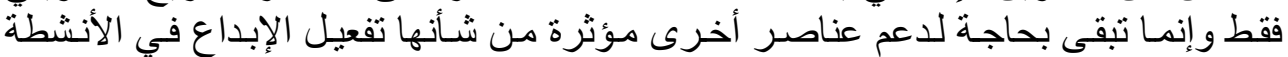

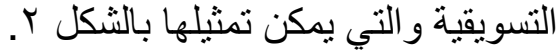

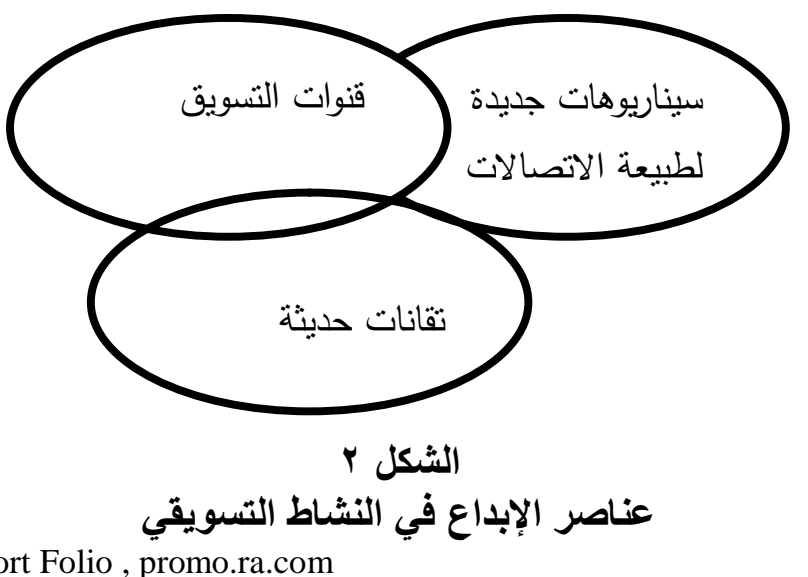

Source :www. port Folio, promo.ra.com

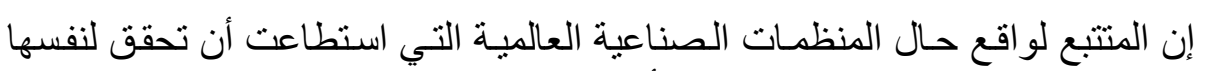

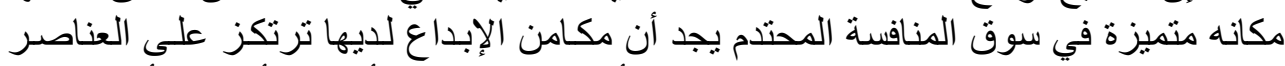

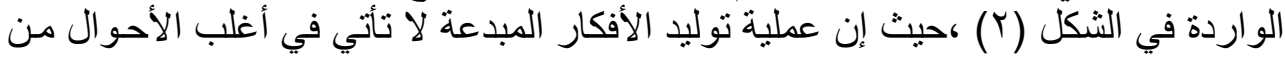

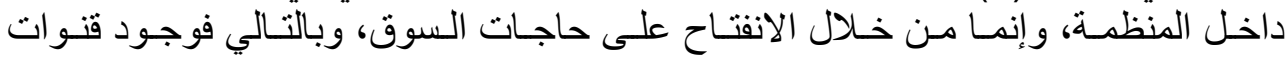

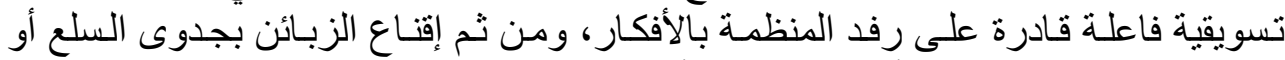

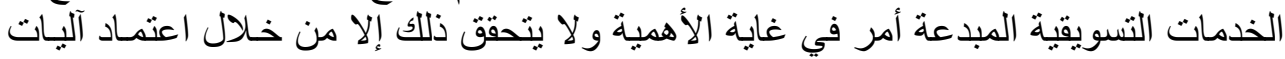




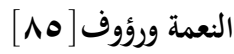

جديدة ووضع سيناريو هات جذابة لنمط الاستهلاك لا تيؤدي إلى بعثرة جهود المنظمة بهذا

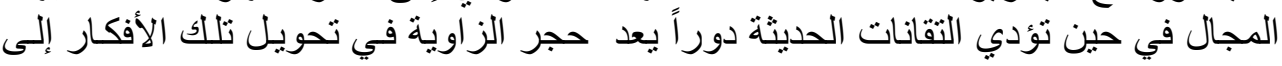

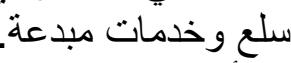

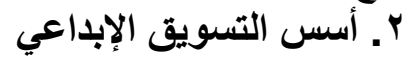

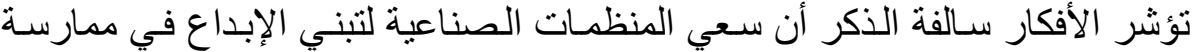

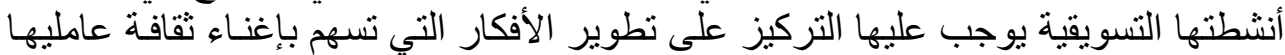

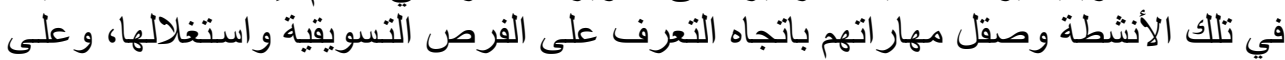
هذا الأساس فإن تفعيل الإبداع في النشاط التسويقي ينطلب تهيئة الأرضية الملائمة لذلك من التهن

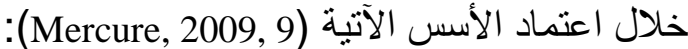
• الإعداد للإبداع: وذللك من خلال تخمين كلفة الإبداع التي تعد المصدر الأول للديمومة

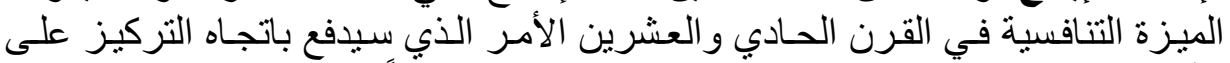

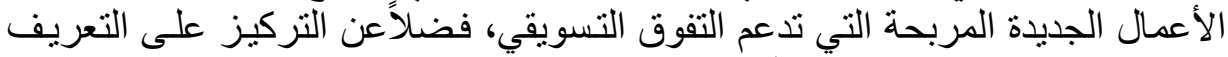

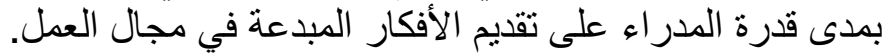

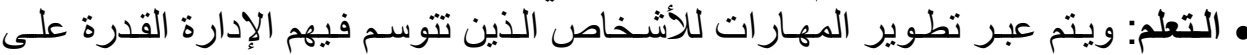

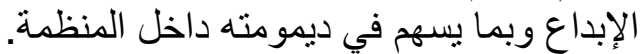

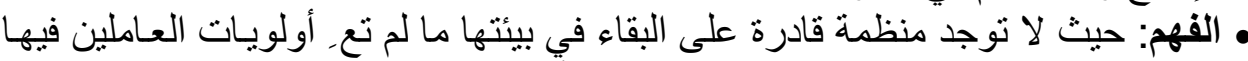

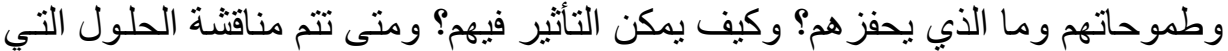

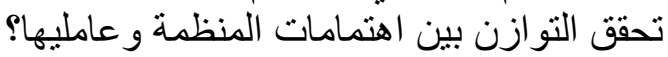

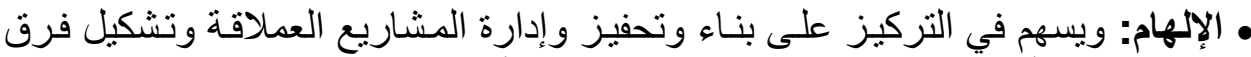

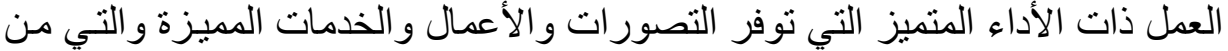
شأنها تقديم الدعم لمواتهة الادئ التحديات التنافسية.

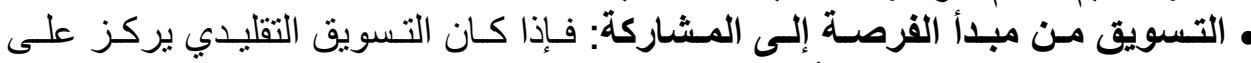

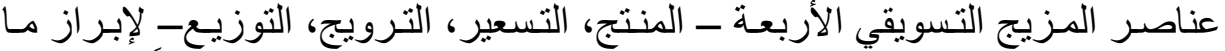

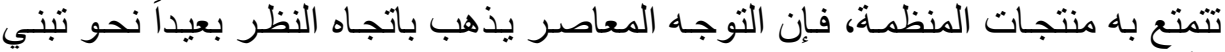

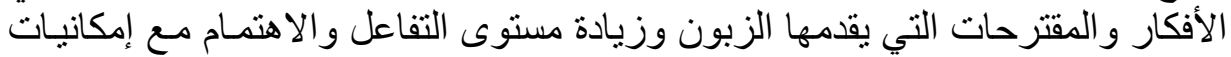

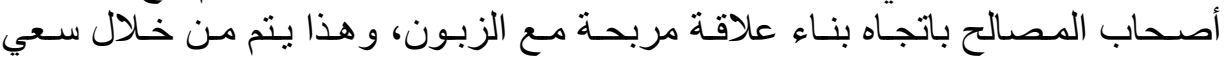

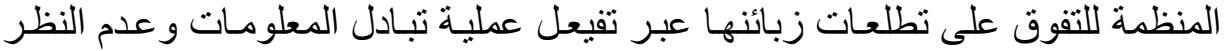

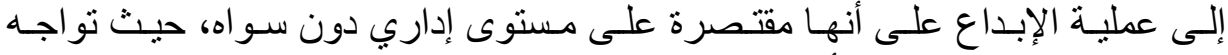

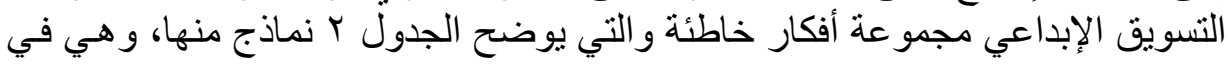
حقيقتها خيال تسير على وفقه الإدار ات التقليدية.

\begin{tabular}{|c|c|}
\hline \multicolumn{2}{|c|}{ 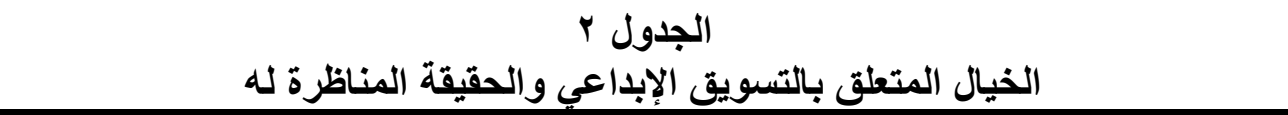 } \\
\hline الحقيقة & الخيال \\
\hline 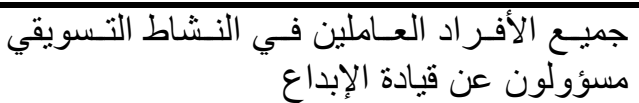 & والتبغي إن تقاد عملية الإبداع عبر أنشطة البحث \\
\hline
\end{tabular}




\begin{tabular}{|c|c|}
\hline 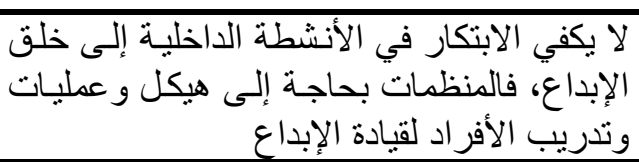 & 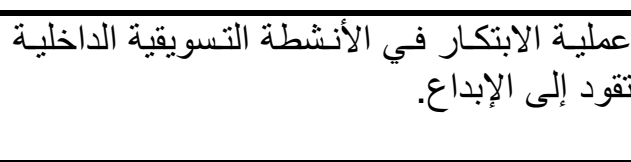 \\
\hline 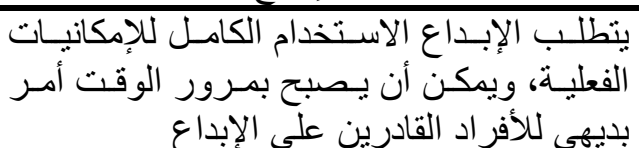 & (خارج نطاق التفكير بالأنشطة الحالية) التع الغريـب \\
\hline
\end{tabular}

Source: Mark ,joshi , 2005, innovations in marketing: Roubst marketing with six sigma principles, journal of industrial marketing, Vol 114 , No 3 p :21

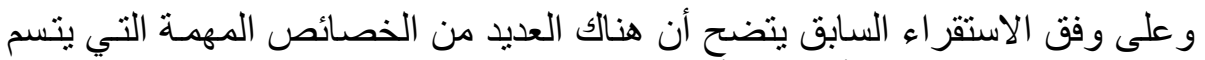

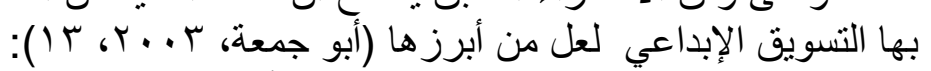

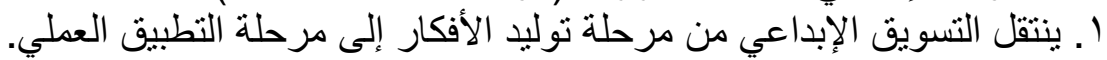

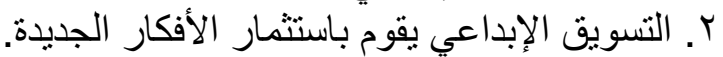

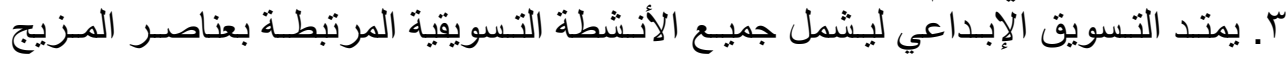
التسويقي.

يتطلب التسويق الإبداعي على الإبداعي وفق ما أوردناه عملية تهيئة مسبقة للأرضية المناسبة

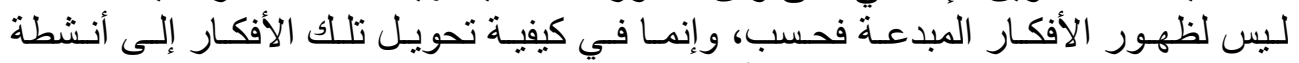

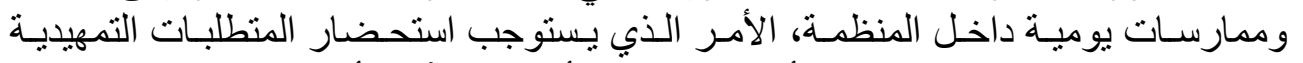

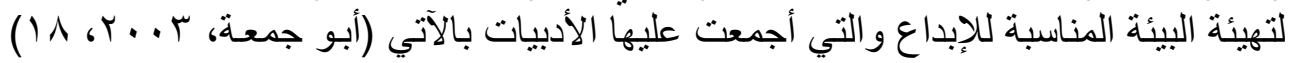
:(Anisa Puri, 2006, 17) ا. متطلبات إدارية: وترتبط بمدى اقتناع إدارة المنظمة بدور التسويق الإبداعي إزاء تفعيل

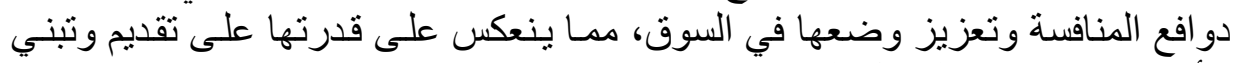
الأفكار المبدعة في المجافة ونعزئ التسويقي.

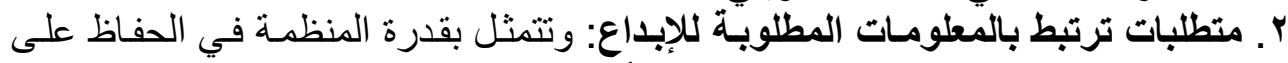

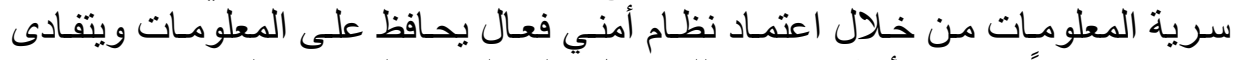

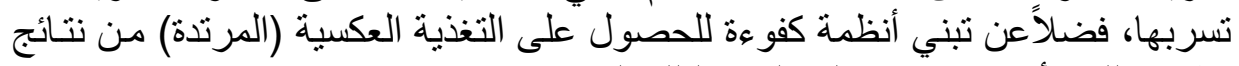

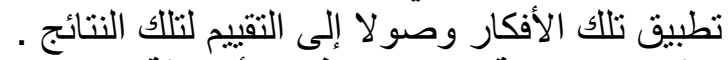

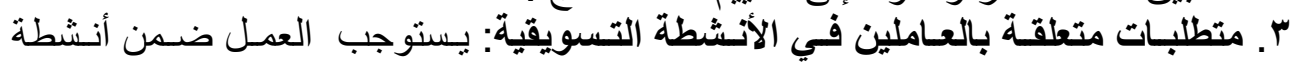

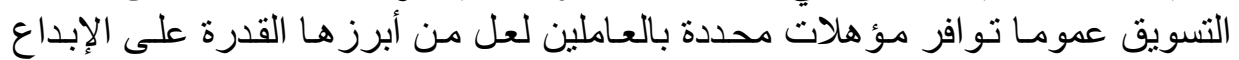

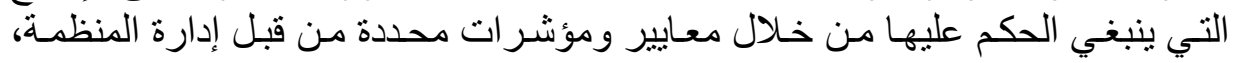

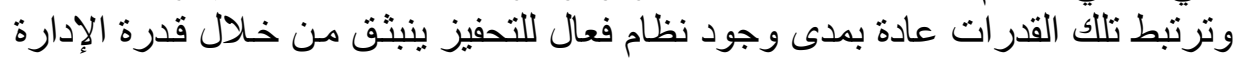

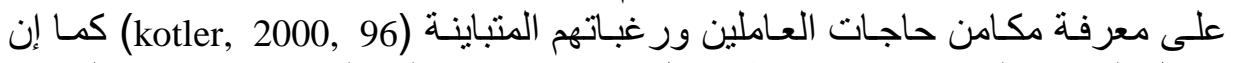

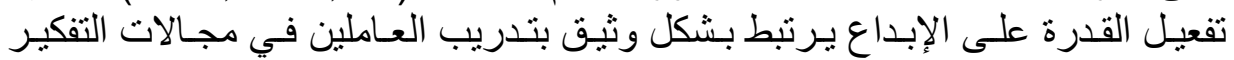

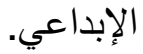

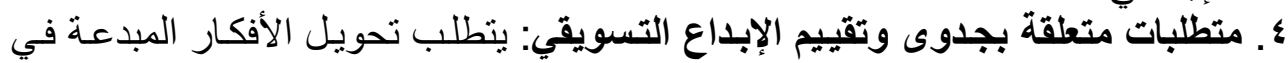

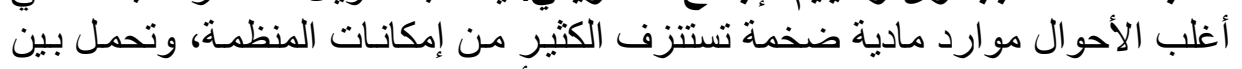

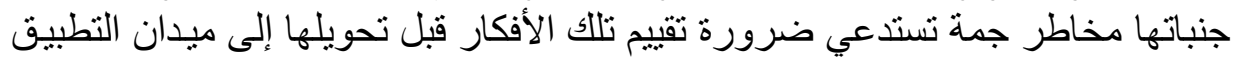




\section{[Av] النعمة ورؤوف}

عبر الاستعانة بهيئات الخبرة والكوادر المتخصصة في مجال دراسـة الجدوى لتجنيب المنظمة مخاطر الفشل في السوق. هـ متطلبات متنوعة: وتتعلق بكل مـا يرتبط بمقاومـة الإبداع التسويقي التي تعد في العديد

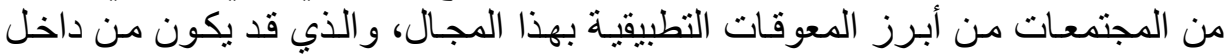

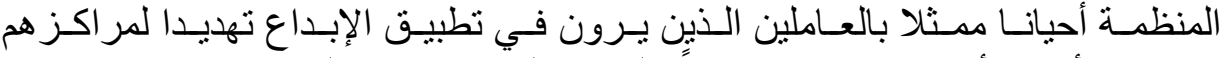

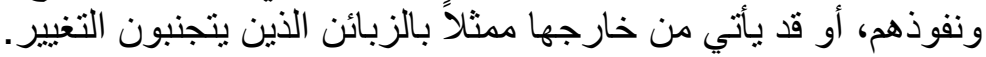

الإطار التطبيقي (الميداني)

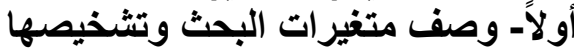
ا ا وصفف إجابـات المبحوثئن حول (محور) التوجهات البيئيـة المعاصرة (المتغير

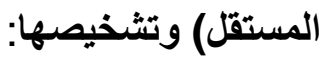

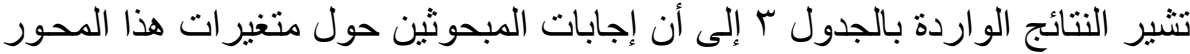

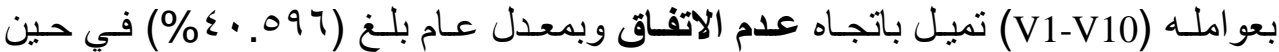

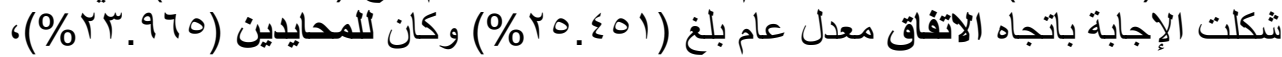

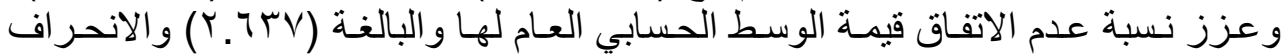

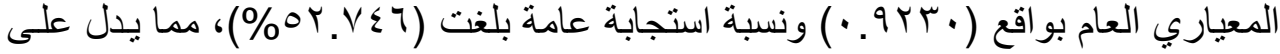

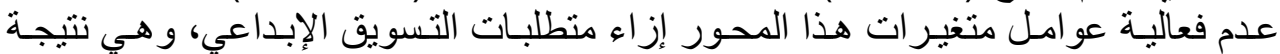

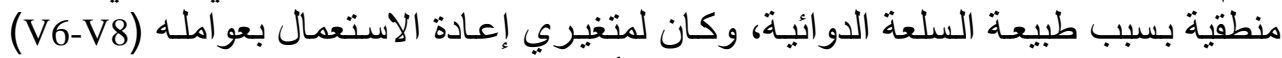

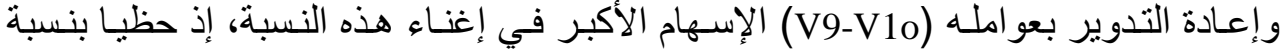

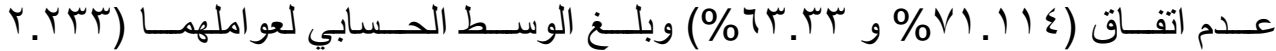

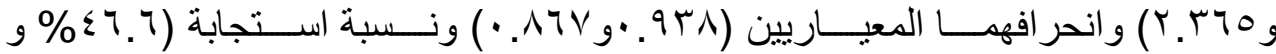

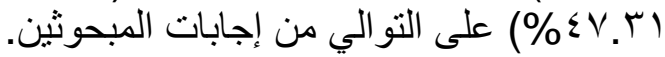

r. وصف إجابات المبحوثين حول (محور) متطلبات التسويق الإبداعي (المتغير المعتمد)

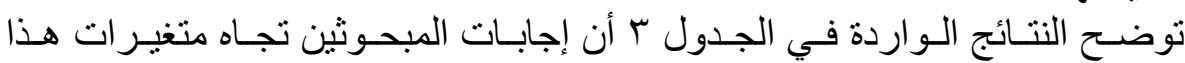

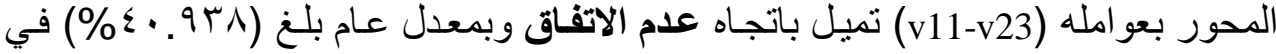

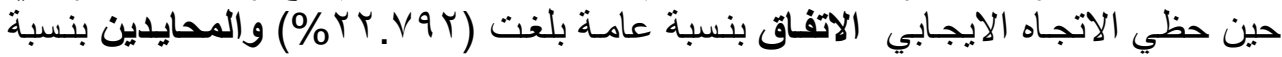

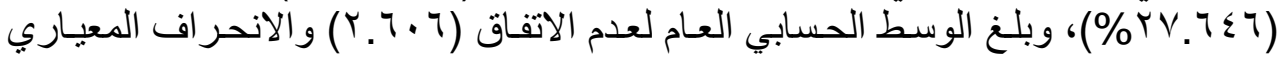

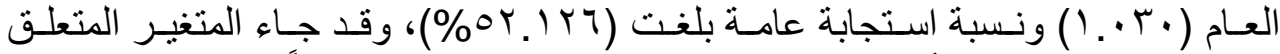

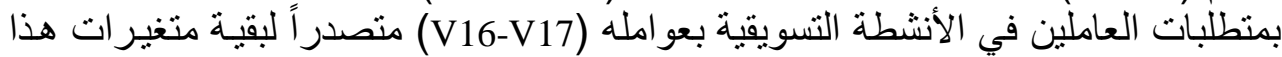

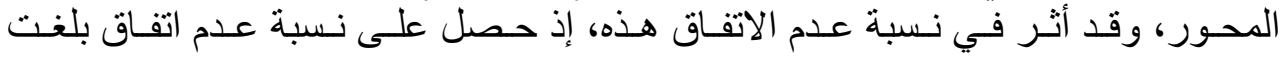

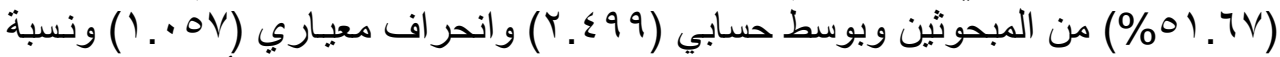

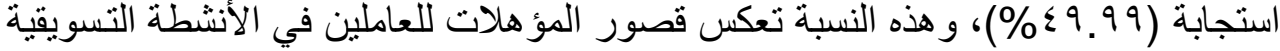

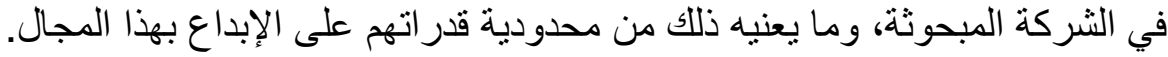

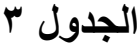

التوزيعات التكرارية والأوساط الحسابية والانحرافات المعيارية ومقياس نسبة الاستجابة لإجابات المبحوثين حول متغيرات محوري البحثث في الثركة المبحوثة 


\begin{tabular}{|c|c|c|c|c|c|c|c|}
\hline \multirow{2}{*}{$\begin{array}{c}\text { الاستجابة } \\
\text { \% }\end{array}$} & \multirow{2}{*}{ الانحرياف } & \multirow{2}{*}{ الحسبابي } & \multicolumn{3}{|c|}{ مقياس الاستجابة } & \multirow[b]{2}{*}{ عو امله (أسئلتها) } & \multirow{2}{*}{$\overline{3}$} \\
\hline & & & الاتفاقُم\% علدم & $\begin{array}{l}\text { المحايد } \\
\%\end{array}$ & الاتفاق\%\% & & \\
\hline $77 .+Y 7$ & A & $\Gamma . \mu \leq$ & $M . T \leq \varepsilon$ & $r \varepsilon .74 \Lambda$ & $\varepsilon \wedge . \cdots \wedge$ & التقليص V1-V5 & \multirow{3}{*}{ 牙金事 } \\
\hline$\sum 7.7$ & $.9 \mu \wedge$ & T.YTr & $v 1.11 \varepsilon$ & $10.00 \mathrm{~V}$ & IT.THV & إعادة الاستعمالV6-V8 & \\
\hline$\sum V . \Gamma 1$ & $\cdot \wedge T \vee$ & T.T40 & אז. זד & YI.TV & $10 . .0$ & إعادة التدويرV10-V10 & \\
\hline or. $V \leqslant T$ & $.9 r \pi$ & T.TTV & $\varepsilon . .097$ & rr.970 & Y0. $\leqslant 01$ & \multicolumn{2}{|l|}{ المعدل العام \% } \\
\hline $0 V .99 Y$ & $\cdot .9 \leqslant \mu$ & r. .99 & $r \wedge . \wedge 9 r$ & $\varepsilon Y . Y Y \varepsilon$ & $r \wedge . \wedge 9$ & إدارية V11-V13 & \multirow{5}{*}{ 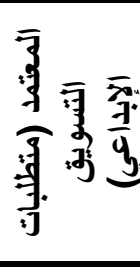 } \\
\hline 01.99 & $1 . v \cdot$ & $r .099$ & r. $4 \mathrm{~V}$ & $r \varepsilon$ & YI.TV & معلومات V14-V15 & \\
\hline$\leqslant 9.99$ & $1.0 \mathrm{~V}$ & r. $\leqslant 99$ & $01.7 \mathrm{~V}$ & 47.770 & 41.770 & العاملين V16-V17 & \\
\hline $01.00 Y$ & $1 . \cdot v \cdot$ & T.OVV & $\varepsilon \varepsilon . \varepsilon 0 T$ & T1.00V & Y0.071 & جدوى V18-V20 & \\
\hline$\sum 9.1 \cdot 7$ & 1.11 & $r . \leqslant 00$ & $\varepsilon r . \cdots \varepsilon$ & Tr.VA & 17.8 & عامة V21-V23 & \\
\hline Or.IYT & 1.4. & $T .7 .7$ & $\varepsilon \cdot .9 \mu \wedge$ & TV.TET & Tr.VAY & لمعدل العام \% & \\
\hline
\end{tabular}

المصدر: الجدول من إعداد الباحثين بالاعتماد على مخرجات البرمجية الإحصائية (SPSS)

\section{ثانياً تحليل نتائج اختبار فرضيتي البحث ومناقشتها}

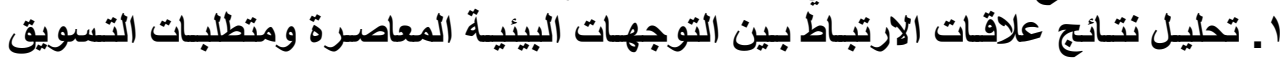

تتجـه هذه الفقرة للتحقق مـن سـريان الفرضية الأولـى، إذ تشير النتائج الـواردة في

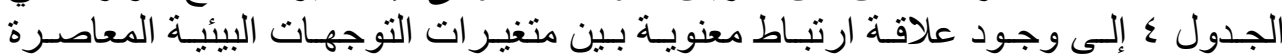

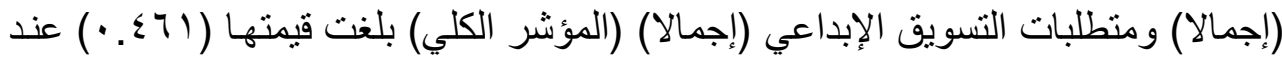

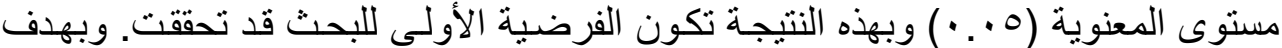
توضيح طبيعة أبعاد علاقات الارتباط بين متغيرات التوجهات البيئية (إجمالا و انفر ادا) فـان

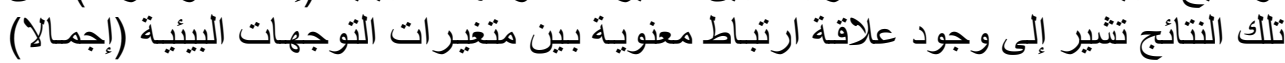

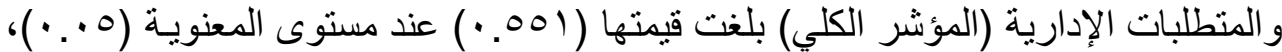

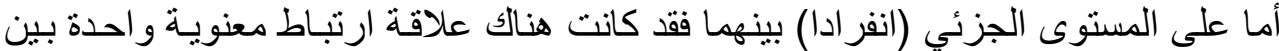

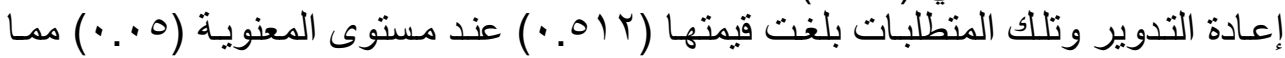

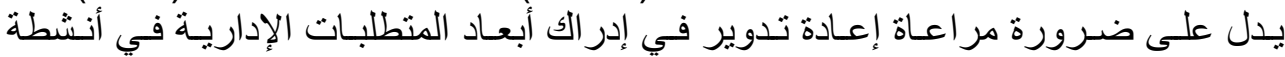

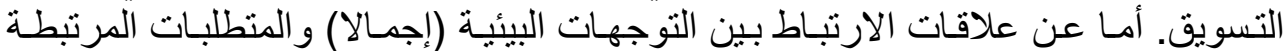

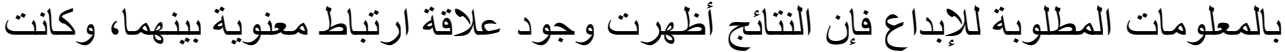

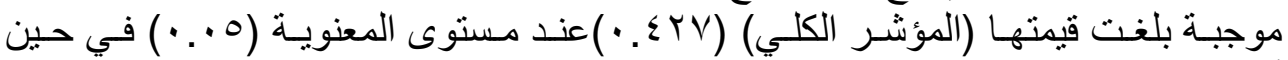

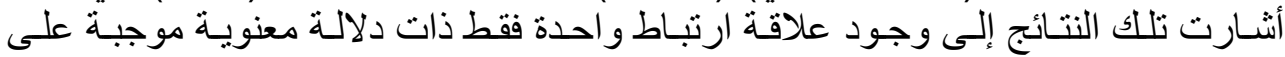

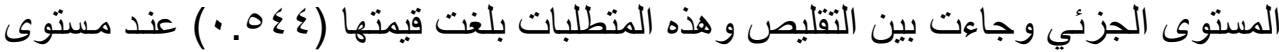

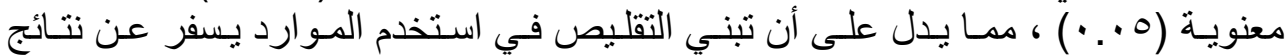

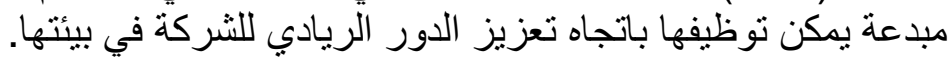

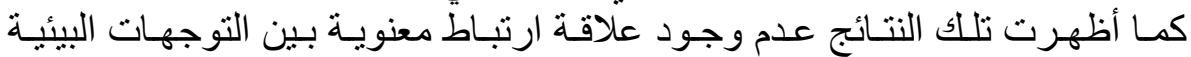

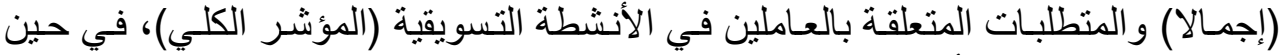

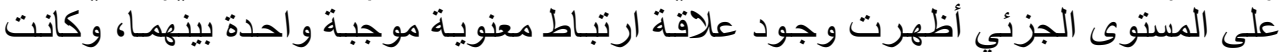




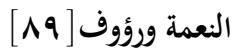

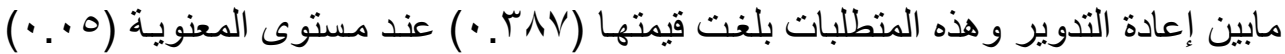

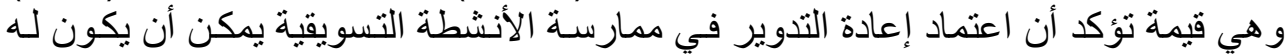

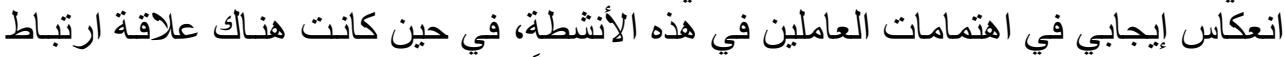

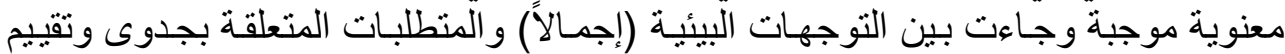

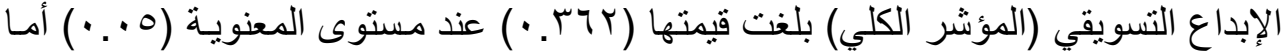

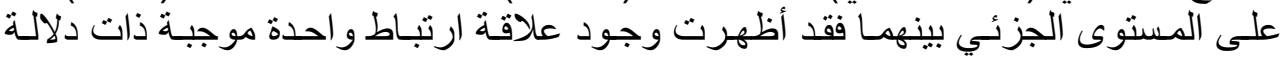

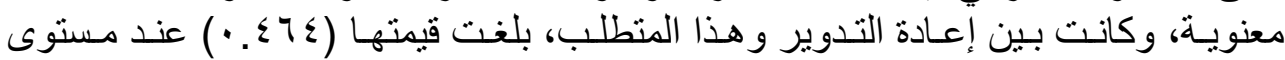

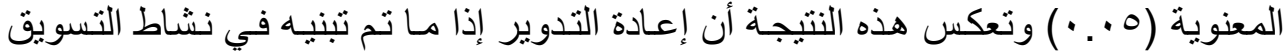
فيستلزم دراسة وتقييم مستمر لمجمل الأنشطة التسويقية.

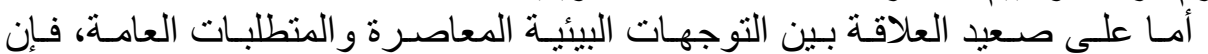

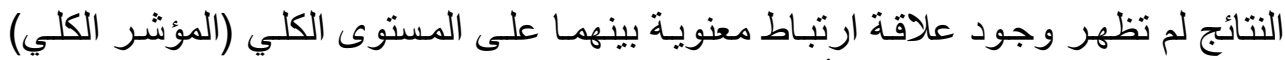

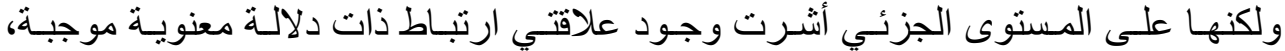

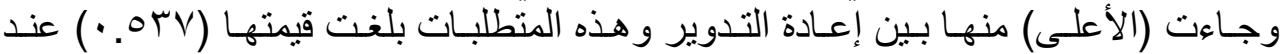
مستوى المعنوية (0. . • ) و هذه القيمة تدل على أهمية دور تفعيل إعادة التدوير في ممارسية مجمل الأنشطة التسويقية.

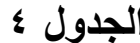

نتائج علاقات الارتباط بين متغيرات التوجهات البياتية ألتئية

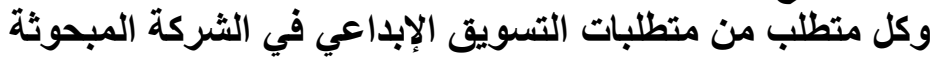

\begin{tabular}{|c|c|c|c|c|c|c|c|}
\hline \multirow{2}{*}{ الكؤشي } & \multicolumn{5}{|c|}{ منطلبات التسويق الإبداعي } & \multirow[t]{2}{*}{ المعتمد } & \\
\hline & عامة & جدوى & العاملين & معلومات & إدارية & & \\
\hline.$\leqslant T V$ & . & ( & . & $.0 \leqslant \leqslant *$ & $.0 \leqslant 7$ & تقليص & \multirow{3}{*}{ 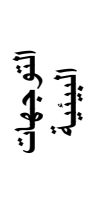 } \\
\hline..$I V T$ & $.17 \varepsilon$ & $\because 9 V$ & $\because 7 \varepsilon$ & .111 & $\cdot r \wedge \wedge$ & إعادة استخدام & \\
\hline.$\varepsilon 9 V^{*}$ & $.0 Y V^{*}$ & $\cdot . \leqslant 7 \leqslant *$ &.$r \wedge \nu^{*}$ & צחי & $.01 r^{*}$ & إعادة تدوير & \\
\hline.$\leqslant 71 *$ &.$\leqslant \leqslant 0$ & . & $\cdot . r \cdot 9$ &.$\Xi Y V^{*}$ & $.001 *$ & \multicolumn{2}{|c|}{ المؤشر الكلي } \\
\hline
\end{tabular}

$* \mathrm{p} \leq 0.05 \quad \mathrm{~N}=30$

المصدر: الجدول من إعداد الباحثين بالاعتماد على مخرجات البرمجية الإحصائية (SPSS)

r. تحليل نتائج علاقات التأثير لعوامل متغيرات التوجهات البيئية المعاصرة في متطلبات الإنيات التسويق الإبداعي ومناقشتها باعتماد أسلوب الانحدار المتدرج (Stepwise)

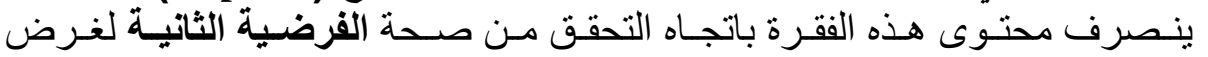

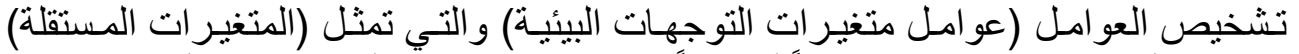

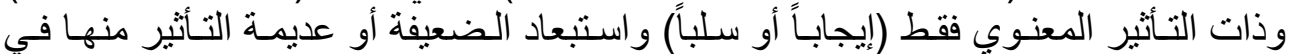

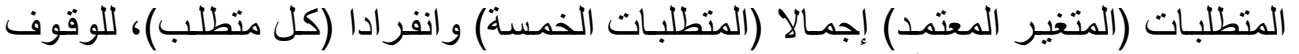

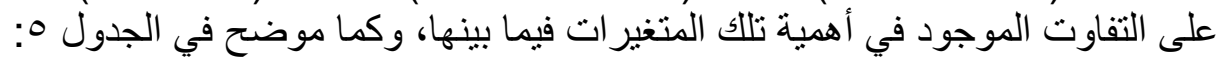


نتائج اختبار تأثير عوامل متغيرات التوجهات البيئية (Stepwise)

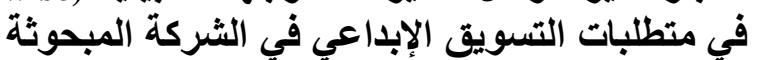

\begin{tabular}{|c|c|c|c|c|c|c|c|c|}
\hline المؤشر & \multicolumn{5}{|c|}{ متطلبات التسويق الإباعي } & \multirow[t]{2}{*}{ المعتمد } & \multirow{2}{*}{\multicolumn{2}{|c|}{ المستقل }} \\
\hline & متنوعة & جدوى & العاملون & معلومات & إدارية & & & \\
\hline .794 & $1 . \wedge \varepsilon$ & . & $\cdot \varepsilon \cdot V$ & .909 & 1.110 & $\mathbf{B}_{0}$ & متغيرات & \multirow{13}{*}{ 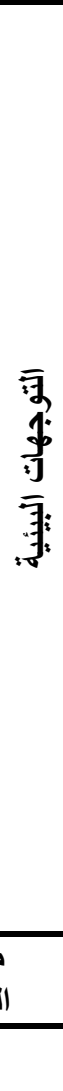 } \\
\hline $\begin{array}{l}r \mid r .{ }^{*} \\
(r .1 . r)\end{array}$ & - & - & - & - & - & $\mathbf{B}_{1}$ & & \\
\hline- & - & - & $\begin{array}{l}\because 090 * * \\
(Y . \vee \leqslant 7-)\end{array}$ & 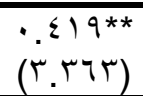 & - & $\mathbf{B}_{2}$ & & \\
\hline $\begin{array}{l}\text { •rצ** } \\
(r . \mu)\end{array}$ & - & - & $\begin{array}{l}\because 7 \cdot r^{* *} \\
(\varepsilon .1 \wedge 9)\end{array}$ & - & $\begin{array}{l}\because \leqslant 97 * * \\
(1.9 \wedge 9)\end{array}$ & $\mathbf{B}_{3}$ & 得。 & \\
\hline $\begin{array}{l}\text { MY** } \\
(\Gamma .19)\end{array}$ & $\begin{array}{l}\cdot T \leqslant)^{*} \\
(Y, V \backslash T)\end{array}$ & $\begin{array}{l}\neg \wedge \varepsilon .{ }^{* *} \\
(\varepsilon .9 \leqslant 9)\end{array}$ & $\begin{array}{l}\because 7 \cdot 7 * * \\
(\varepsilon .7 \cdot)\end{array}$ & $\begin{array}{l}. r r{ }^{*} \\
(\cdot g r r)\end{array}$ & - & $\mathbf{B}_{4}$ & & \\
\hline - & - & - & $\begin{array}{l}\because \mu \vee V^{*} \\
(r . \mu \wedge \tau)\end{array}$ & - & - & $\mathbf{B}_{5}$ & & \\
\hline - & - & - & - & - & - & $\mathbf{B}_{6}$ & $\bar{a}$ & \\
\hline - & - & - & - & $\begin{array}{l}\cdot r r_{-*} \\
(r . r \cdot \varepsilon-)\end{array}$ & - & $\mathbf{B}_{7}$ & $\overline{3}$ & \\
\hline- & - & - & - & - & - & $\mathbf{B}_{8}$ & & \\
\hline- & - & - & - & - & - & $\mathbf{B}_{9}$ & \multirow{2}{*}{ 牙 } & \\
\hline $\begin{array}{l}\because . Y 1 \leqslant * \\
(Y .100)\end{array}$ & $\begin{array}{l}\because \varepsilon \vee \mu \star \star \\
(\Gamma . \wedge \wedge \vee)\end{array}$ & - & - & $\begin{array}{l}\because Y \vee Y^{*} \\
(Y . \Sigma Y Y)\end{array}$ & $\begin{array}{l}. \Gamma \leqslant *^{*} \\
(.0 \wedge 0)\end{array}$ & $\mathbf{B}_{10}$ & & \\
\hline . & $\cdot . \leqslant ा र$ & $.7 \leqslant V$ & $\cdot r 99$ & . $r q \varepsilon$ & זדצ. & $\mathbf{R}^{2}$ & التحديد & \\
\hline 19.71. & 19.009 & $r \leqslant . \leqslant 97$ & 11.947 & 11.71. & 10.9 .9 & محسوبة & $\mathbf{F}$ & \\
\hline
\end{tabular}

*P $\leq 0.05, * * \mathrm{P} \leq 0.01, \quad$ المحسوبة = ( ) $\mathrm{t}, \mathrm{N}=30$, df $(1,28)$

المصدر: الجدول من إعداد الباحثين بالاعتماد على مخرجات البرمجية الإحصائية (SPSS)

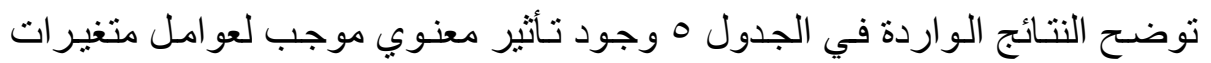

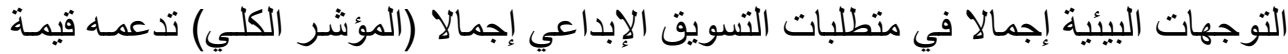

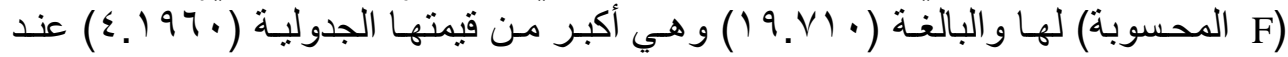

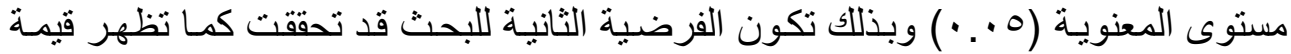

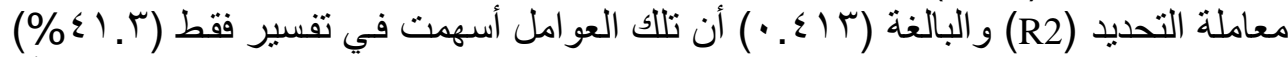

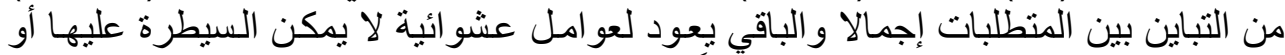

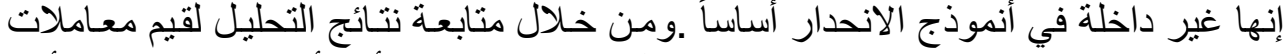

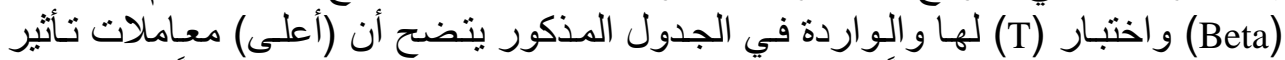

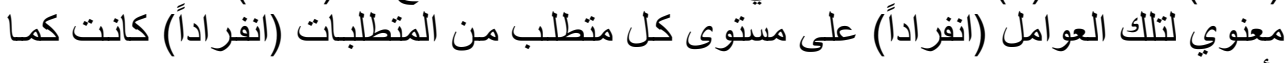




\section{النعمة ورؤوف] [ [9]}

- التأثير المعنوي الموجب للعامل (V3) و المتعلق (باستخدام الشركة تقنيات تصنيع مغلقة الإنة

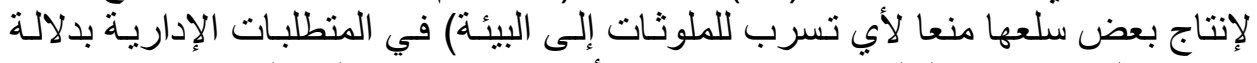

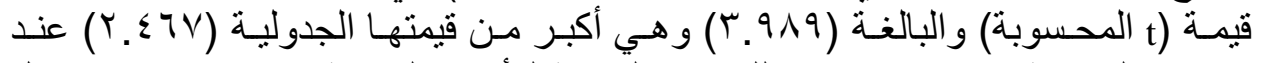

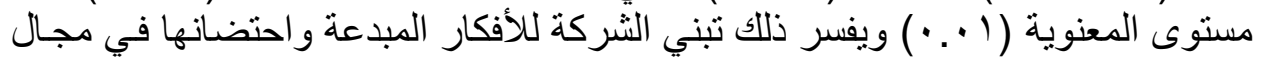
تفعيل اعتماد تقنيات التصنيع المغنيع المغلقة.

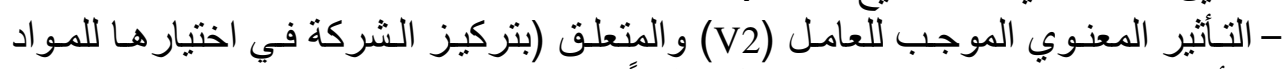

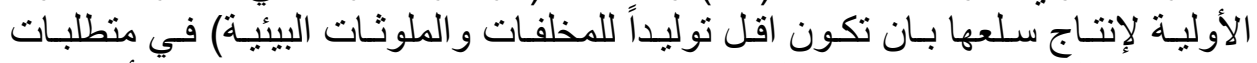

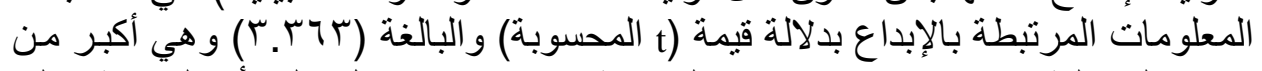

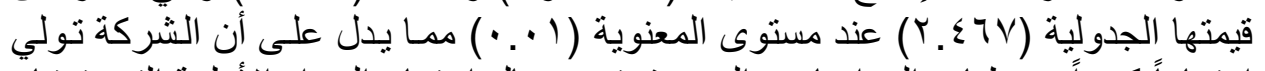

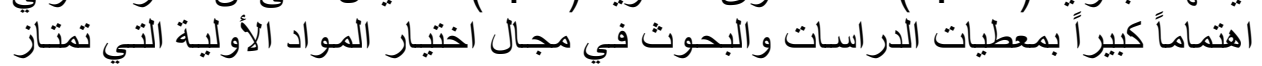

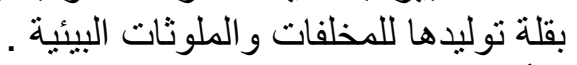

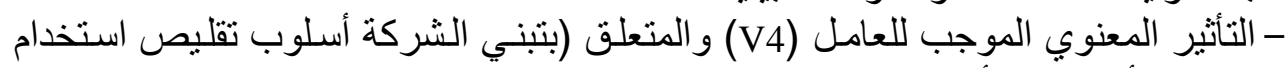

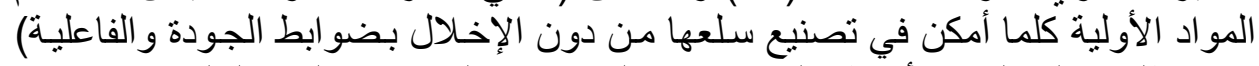

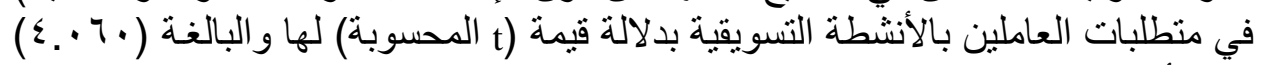

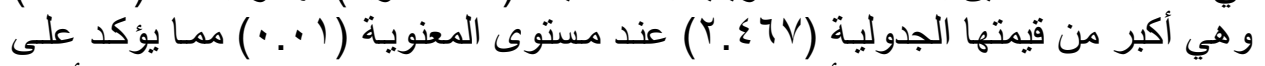

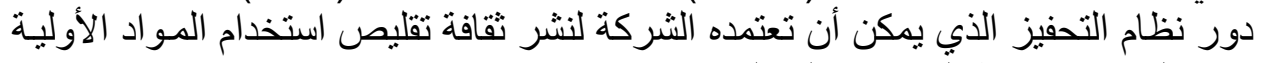

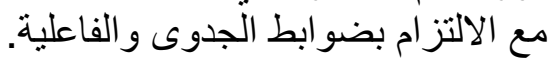

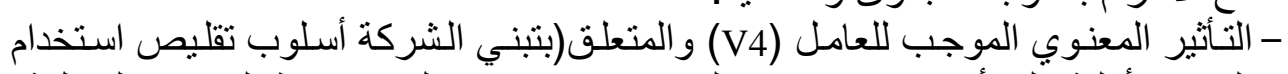

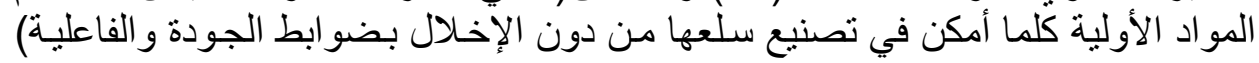

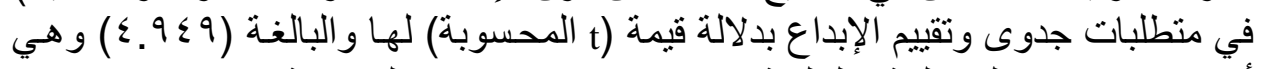

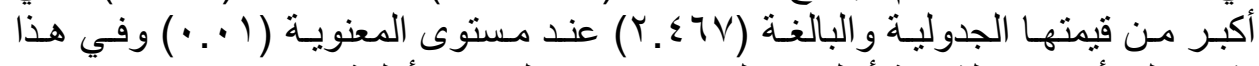

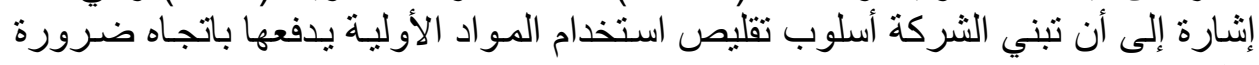
تطوير كو ادر ها وتنشجيع قدر اتهم الإبداعية.

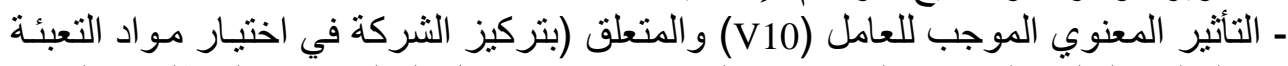

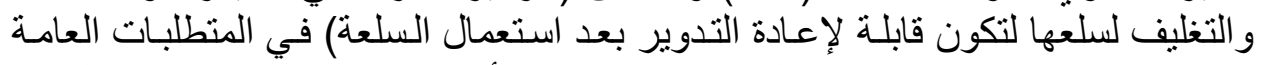

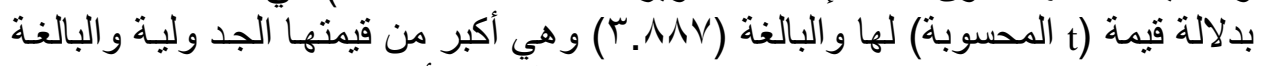
(Y ع _TV)

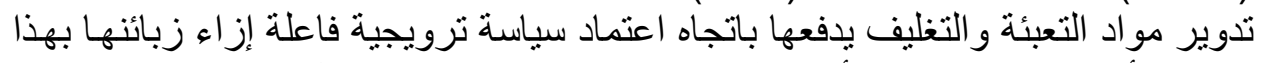

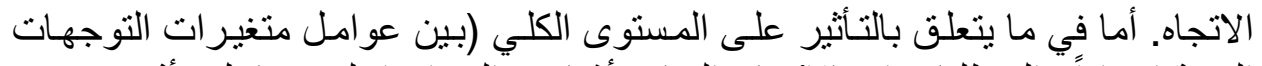

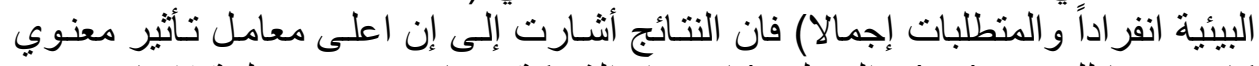

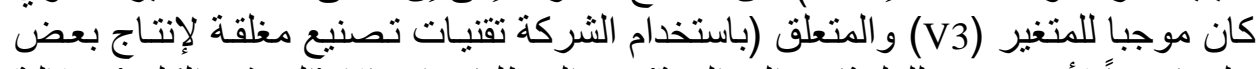

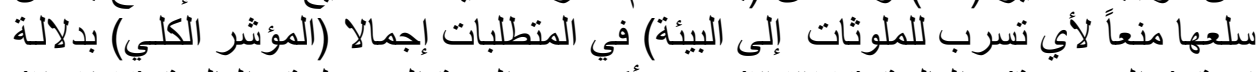

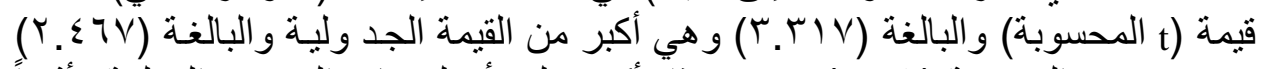

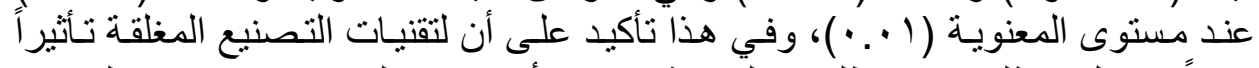

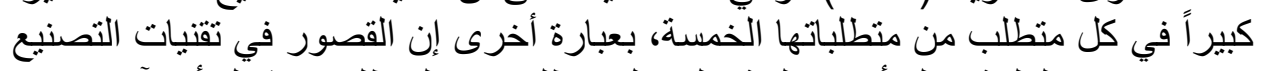

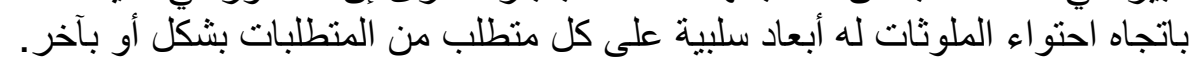




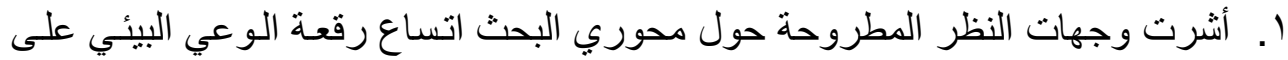

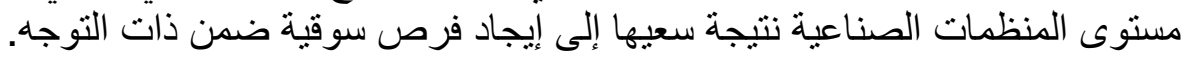

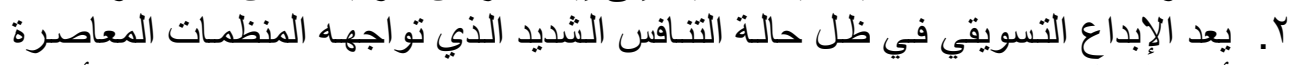

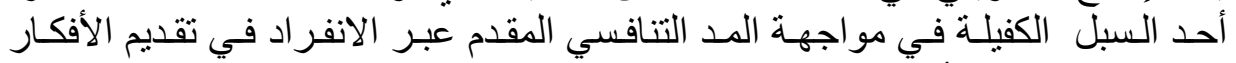
المبدعة في مختلف أوجها النشاط التسويقي.

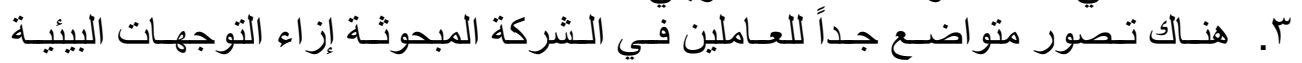

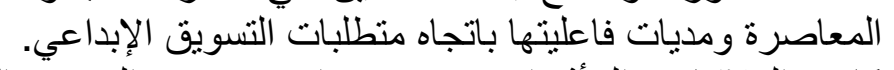

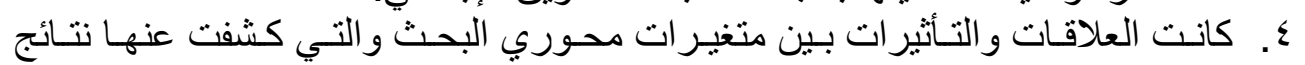

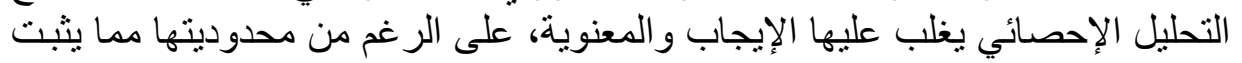
صحة فرضيتي البحث.

ا. . ضرورة سعي الثركة المبحوثـة الى تبنـي التوجيهات البيئية المعاصـرة في ممارسـاتها

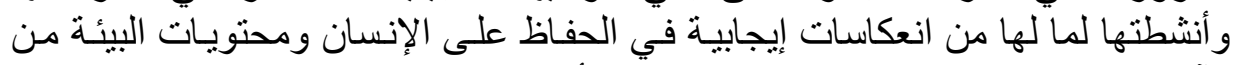

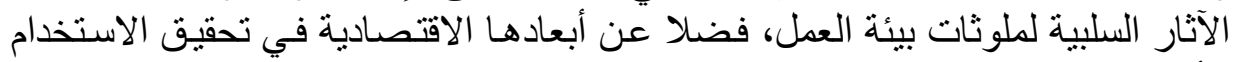
الامثل للموارد.

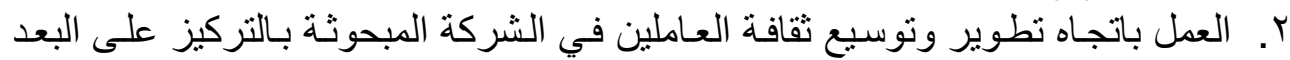

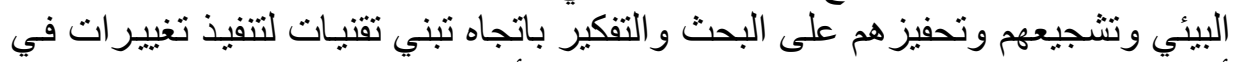

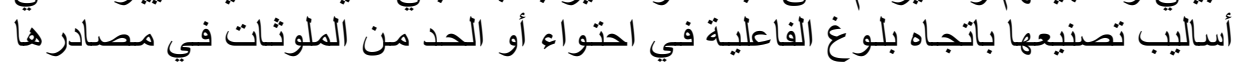

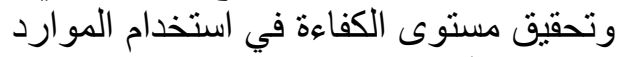

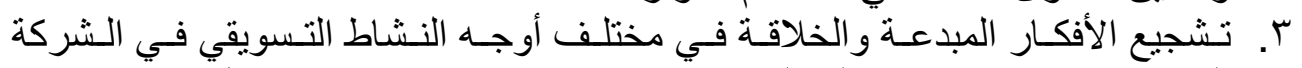

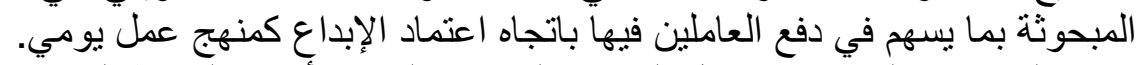

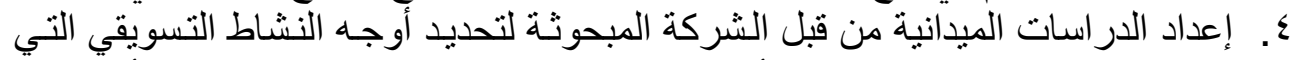

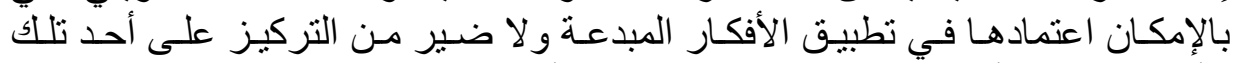

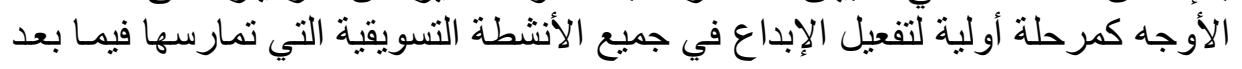

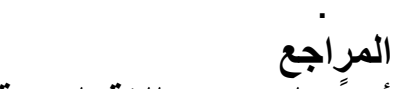

أولاً المراجع باجع اللغة العربية

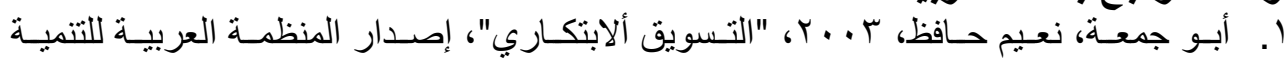

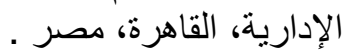

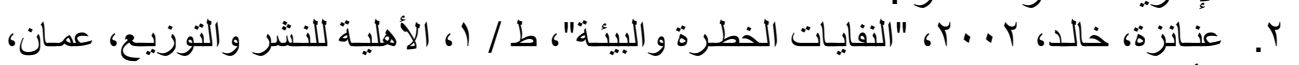
الأردن. r. الفز اللي، أسـامة، 999 (1، "إعـادة التـدوير كـأداة لحمايـة البيئة، دور هـا ومنطلبـات نجاحهـا"، الثركة العربية للالكترونيات، طر ابلس، ليبيا.

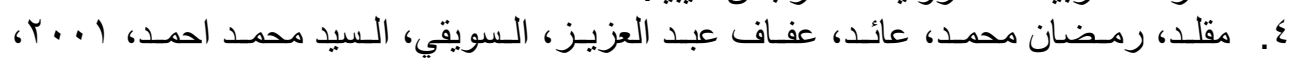

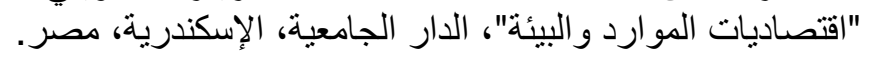

ثانياً- المراجع باللغة الأجنبية

1. Anisa puri, 2006, Innovative marketing, Journal of Economic and political, August ,Vol 5. 


\section{النعمة ورؤوف[ب؟}

2. Judith mercure, 2009, The Great ideas for marketing innovations, www. Proton Europe innovation natural research. Com.

3. Kotler,Philip,2000 ,Marketing Management ,the millennium edi.printed .USA.

4. Mrak Joshi, 2005, Innovations in Marketing: Roubst marketing with six sigma principles ,Journal of industrial marketing.Vol.114,No .3.

5. Peter vervest, 2005, How to win customers in the Digital world, Prentice - Hall. Co. U.K.

6. Richard G. Kraus and Joseph E. Curtis, 2001 ,Creative Marketing, McGraw- Hill Higher education N.Y.USA

7. www. Port Folio. Promo. Ra.com. epa

8. www. wlkipedia.org /wiki/ recycling .com 2009.

9. www.Khayma.Com . 